\title{
Metabolic and Behavioral Features of Acute Hyperpurinergia and the Connection to Autism Spectrum Disorder
}

\author{
Zarazuela Zolkipli-Cunningham \\ University of California San Diego School of Medicine \\ Jane C. Naviaux \\ University of California San Diego School of Medicine \\ Tomohiro Nakayama \\ University of California San Diego School of Medicine \\ Charlotte M. Hirsch \\ University of California Irvine \\ Jonathan M. Monk \\ University of California San Diego School of Medicine \\ Kefeng Li \\ University of California San Diego School of Medicine \\ Lin Wang \\ University of California San Diego School of Medicine \\ Thuy P. Le \\ University of California San Diego School of Medicine \\ Simone Meinardi \\ University of California Irvine \\ Donald Blake \\ University of California Irvine
}

Robert K. Naviaux ( $\square$ maviaux@health.ucsd.edu )

University of California San Diego School of Medicine https://orcid.org/0000-0001-5832-2297

\section{Research}

Keywords: purinergic signaling, mitochondria, metabolism, innate immunity, metabolic memory

Posted Date: August 31st, 2020

DOI: https://doi.org/10.21203/rs.3.rs-63567/v1

License: @ (i) This work is licensed under a Creative Commons Attribution 4.0 International License. Read Full License 


\section{Abstract}

Background. Since 2012, studies in mice, rats, and humans have suggested that abnormalities in purinergic signaling may be a final common pathway for many genetic and environmental causes of autism spectrum disorder (ASD). The current study in mice was conducted to characterize the bioenergetic, metabolomic, breathomic, and behavioral features of acute hyperpurinergia triggered by systemic injection of the purinergic agonist and danger signal, extracellular ATP (eATP).

Methods. Responses were studied in C57BL/6J mice with ASD-like behaviors in the maternal immune activation (MIA) model and controls. Basal metabolic rates, respiratory exchange ratios $\left(\mathrm{RER}=\mathrm{VCO}_{2} / \mathrm{VO}_{2}\right)$, and locomotor activity were measured in CLAMS cages. Plasma metabolomics measured 401 metabolites. Breathomics measured 98 volatile organic compounds.

Results. A $0.5 \mu \mathrm{mol} / \mathrm{g}$ dose of ATP dropped whole body oxygen consumption by $74 \% \pm 6 \%$ (mean \pm SEM, $5,303$ to $1,382 \mathrm{ml} / \mathrm{kg} / \mathrm{hr}, \mathrm{p}<0.0001)$ and rectal temperature by $6.2^{\circ} \pm 0.3^{\circ} \mathrm{C}(\mathrm{p}<0.0001)$ in 30 minutes. Over 200 metabolites from 37 different biochemical pathways where changed. MIA animals were hypersensitive to the metabolic and behavioral responses triggered by eATP and poly(IC). Breathomic and metabolomic analysis revealed changes in folate-methylation-1-carbon, purines, pyrimidines, acyl-carnitines, glycolysis, aromatic and branch-chain amino acids, Krebs cycle, glutathione, urea cycle, phospholipids, sphingolipids, eicosanoids, cholesterol, bile acids, vitamins, and microbiome metabolism similar to children with ASD.

Limitations. The responses to ATP were studied in only a single genetic strain of mice (C57BL/6J). Although similar to metabolic results reported in FVB mice and a small clinical trial in children with ASD, the generalizability of these results to larger studies in humans is unknown. The chronic effects of repeated postnatal ATP exposures were not tested.

Conclusions. Acute hyperpurinergia produced metabolic and behavioral changes in mice that were similar to those found in children with ASD. These behaviors and metabolic changes were associated with mitochondrial functional changes that were profound but reversible.

\section{Introduction}

Over the past decade our group has tested a new unifying hypothesis for the origin and treatment of autism spectrum disorder (ASD) in animal models [1-3] and a small human clinical trial [4]. This new hypothesis proposes that the behavioral symptoms and neurobiology of ASD are the result of a new kind of metabolic syndrome that arises from abnormalities in purinergic signaling. Purinergic signaling was first described by Geoffrey Burnstock in 1970 [5], and refers to the action of purines like ATP, ADP, AMP, and adenosine, and some pyrimidines like UTP and UDP-glucose, when they bind to specific cellular receptors [6]. Interestingly, ATP or its metabolites have also been found to be co-neurotransmitters and neuromodulators at every immunologic [7, 8] and neural synapse that has been studied to date [9]. Persistent abnormalities in purinergic signaling can be traced to a new functional state of the cell and its neighbors. This new functional state is maintained by mitochondrial-nuclear crosstalk and is called the cell danger response (CDR) [10]. Because this new metabolic syndrome traces to the evolutionarily conserved cell danger response, the new conceptual 
framework for the origin and treatment of ASD can be called the CDR hypothesis. Experiments have shown that the CDR is not limited to disturbances in ATP metabolism. The CDR is a highly coordinated, multisystem response that involves hundreds of metabolites and over 30 different metabolic pathways. Once deployed, the metabolic changes of the CDR propagate and cause changes in gene expression, cytokines, methylation, neuroendocrine and autonomic circuits, the microbiome, the immune system, and behavior. Despite the multisystem nature of the CDR, a picture is emerging that shows disturbances in purinergic signaling are at or near the root of the tree of all the changes that occur when a cell is threatened by genetic or environmental danger.

All stressed cells release ATP in proportion to the degree of environmental threat through stress- and redoxgated pannexin/P2X7 and other channels in the plasma membrane, and by vesicular export $[11,12]$. The stress can come in the form of positive threats like infection, poisoning, genotoxicity, physical or psychological trauma. Stress can also come from negative threats like deficiencies in oxygen, water, calories, vitamins, nutrients, or even gravity [13]. Each of these stresses can lead to an increase in ATP release. Extracellular ATP then serves as a pro-inflammatory molecule and damage associated molecular pattern (DAMP) $[14,15]$ that is an effector of the CDR. The release of ATP to the extracellular space has the effect of decreasing intracellular energy reserves, prompting further adaptive changes in mitochondria, metabolism, and gene expression. The words used to describe these adaptive changes in response to changing environmental conditions have varied according to the experimental system being studied. When studying memory in neurons, the adaptive changes have been called long-term potentiation [16]. When studying other cell types and organisms, this highly conserved adaptive response has been called allostasis [17], hormesis [18], and adaptive homeostasis [19]. Each term is used to describe a different aspect of the same biology. The molecular aspects of the CDR include the integrated stress response (ISR) [20]. The systemic features of the CDR are coordinated by remote sensing and signaling (RSS) mechanisms that involve ATP and other metabolites like glutamate that bind to receptors, regulate, or are conducted by solute carriers (SLCs) and ABC transporters [21]. Earlier work on the connection between the immune response and cellular damage and danger by Polly Matzinger and Ephraim Fuchs was published in the 1990s [22, 23]. The systemic, or wholebody CDR starts with the cellular ISR that is coordinated by mitochondria [20,24,25]. More recent work has now tied the CDR to healing, aging, early life stress events that can change the trajectory of child development [26], and the cellular response to environmental pollution [27-29].

Mitochondria not only coordinate the CDR by producing $90 \%$ of the ATP in the cell, regulating cellular redox, energy metabolism, and epigenetics [30,31], but also play a pivotal role in both the response to [29], and regeneration after injury [32]. Purinergic signaling abnormalities have also been found by gene ontology analysis of transcriptomic data from post-mortem brains of children with ASD [33]. The purinergic signaling abnormalities found in that study were correlated with ASD behaviors and with a coordinated set of abnormalities in mitochondrial oxidative phosphorylation, protein and lipid synthesis. Other metabolic markers of the CDR, like changes in tryptophan, methionine, folate, and glutathione metabolism have been described in several cohorts of children with ASD also trace to a new state of mitochondrial function [34-36].

The first genetic evidence that abnormalities in purinergic signaling might be involved in the pathogenesis of ASD came in 1969 [37]. This was the report of a child with ASD, high uric acid from increased purine metabolism, and a mutation in phosphoribosyl pyrophosphate synthase (PRPPS) that eliminated feedback 
control and led to superactivity of this rate-limiting enzyme in de novo purine synthesis [38]. Over the next 50 years, several other examples of genetic disorders of purine and pyrimidine metabolism that cause ASD have been reported [39]. Point mutations in mitochondrial DNA have also been shown to cause ASD [40]. Based on these genetic leads, we tested the antipurinergic drug suramin to treat the Fragile $X$ genetic model of autism in mice. That study found the top metabolic pathway that changed in association with the correction of ASD-like behaviors was purines [1].

\section{Aims of the study}

In the current mouse study, we used a combination of bioenergetic, breathomic, metabolomic, and behavioral analysis for two aims: 1 ) to test the effect of ATP injection in typically developing control animals as an experimental model of hyperpurinergia, and 2) to test the effects of postnatal ATP or poly(IC) injection in animals with pre-existing ASD-like behaviors in the maternal immune activation (MIA) model [41-43].

\section{Materials And Methods}

\section{Animals and Husbandry}

All studies were conducted in facilities accredited by the Association for Assessment and Accreditation of Laboratory Animal Care International (AAALAC) under UCSD IACUC-approved animal subjects protocol number S06135. C57BL/6J mice were obtained from Jackson Laboratories (Bar Harbor, ME) and maintained on ad libitum Harlan Teklad 8604 mouse chow and water. Animals were housed at an ambient temperature of $22-24^{\circ} \mathrm{C}$ and humidity of $40-50 \%$, in a controlled access vivarium with a $12 \mathrm{~h}$ light-dark cycle; lights on at 7 am and off at $7 \mathrm{pm}$. The thermoneutral zone for adult mice about $25-30$ grams in weight is $29-31^{\circ} \mathrm{C}$ [44]. Below this temperature, additional calories must be burned to maintain body temperature. The human biological age equivalent for the C57BL/6J strain of laboratory mouse (Mus musculus) was estimated from the following equation: 12 years for the $1^{\text {st }}$ month, 6 years for the $2^{\text {nd }}$ month, 3 years for months $3-6$, and 2.5 years for each month thereafter $[2,45]$. Therefore, an 8 -month old mouse would be about 35 years old $(=12+6+3 \star 4+2.5 \star 2$ $=35$ years) on a human timeline.

\section{Reagents}

ATP, ADP, GTP, adenosine (Ado), cAMP, cGMP, UTP, CTP, TTP, and poly(IC) were purchased from Sigma. Sterile saline was made from endotoxin-free, nuclease free $\mathrm{H}_{2} \mathrm{O}$ and used as the solvent for all solutions.

\section{Nucleotide administration}

All nucleotide and drug challenge experiments were conducted between 9:00 am and $1 \mathrm{pm}$. Mice were given intraperitoneal (IP) doses of nucleotides or saline at an equal volume of $20 \mathrm{ll} / \mathrm{g}$. Intravenous doses were administered by lateral tail vein injection in maximum volumes of $5 \mu \mathrm{l} / \mathrm{g}$. Doses up to $0.5 \square \mathrm{moles} / \mathrm{g}$ were given as a $25 \mathrm{mM}$ solution. Pilot dose-response experiments revealed that higher doses (>0.5 $\square \mathrm{moles} / \mathrm{g}$, as 50-100 $\mathrm{mM}$ solutions) of ATP IP resulted in non-linear phenotypic dose responses as they approached saturation. To initiate the maternal immune activation (MIA) model, pregnant dams received an IP injection of poly(IC) (Sigma-Aldrich Cat\# P9582;) (0.17 A260 U/g; 2 mg/kg IP) on gestational day E12.5 and E17.5. Control dams 
received normal saline ( $0.15 \mathrm{M} \mathrm{NaCl} ; 5 \mu \mathrm{l} / \mathrm{g} \mathrm{IP})$ on E12.5 and E17.5. Pregnant dams were provided with nesting material and left undisturbed until offspring were weaned at 3-4 weeks of age. The postnatal challenge dose of poly (IC) $(0.17$ A260 U/g; $2 \mathrm{mg} / \mathrm{kg}$ IP) was tested in 8-9-month-old animals. Daily temperature was recorded for 14 days, then weekly for 4 weeks after poly(IC) administration.

\section{Metabolomics}

Blood was collected by submandibular vein lancet [46] into lithium-heparin BD microtainers (Cat\# 365971, Becton-Dickinson) and inverted 10 times. Plasma was separated by centrifugation at $1500 \mathrm{~g}$ for $5 \mathrm{~min}$ in an Eppendorf microfuge and frozen at $-80^{\circ} \mathrm{C}$ until use. Blood draws were performed between the hours of 9 am and $1 \mathrm{pm}$. Targeted, broad-spectrum, metabolomic analysis of 613 metabolites from 63 biochemical pathways was performed by LC-MS/MS as described [47] with minor modifications. A total of 401 of the 613 targeted metabolites were measurable in the plasma of both males and females. L-cysteine was not measured independently because of oxidation to its disulfide cystine that occurred in whole plasma with storage.

\section{Breathomics}

Breathomic analysis of natural gases and volatile organic compounds in mice was performed as described with minor modifications [48]. Six 10-month old C57BL/6J male mice were used in this study. Three mice received intraperitoneal injections with physiologic saline, and 3 were injected with $0.5 \mu \mathrm{mol} / \mathrm{g}$ ATP $(0.6 \mathrm{ml}$ IP of a $25 \mathrm{mM}$ solution in 30-gram animals). Samples of exhaled mouse breath were collected from a $10 \mathrm{~L}$ glass bulb containing a mouse fitted with three sampling ports. One of the sampling ports was connected to a $1.9 \mathrm{~L}$ electropolished stainless steel canister via a Swagelok Nupro bellows valve using stainless steel flex tubing. Prior to sampling, the canisters were baked at $150^{\circ} \mathrm{C}$ for 24 hours, flushed with ultra-high purity helium, and vacuumed to $10^{-2} \mathrm{~mm} \mathrm{Hg}$. Upon injection, each mouse was immediately placed in the sampling vessel and breath samples were collected for 20 seconds at 1, 5 and 10-minute intervals into three separate $1.9 \mathrm{~L}$ canisters for each mouse. For purposes of this analysis, the results for all 3 time points were pooled and averaged. Room air samples were collected before and after the study for background air analysis. The samples were analyzed for $\mathrm{CO} / \mathrm{CO}_{2}$ and $\mathrm{CH}_{4}$ in addition to a list of about 100 volatile organic compounds (VOCs) using the 6-column-detector gas chromatography system in the Rowland/Blake laboratory at UC Irvine. The $\mathrm{CO} / \mathrm{CO}_{2}$ measurements were carried out using a Carbosphere $80 / 100$ packed column with a flame ionization detector (FID) for $\mathrm{CO}$ and a thermal conductivity detector (TCD) for $\mathrm{CO}_{2} . \mathrm{CH}_{4}$ determination was performed on a separate GC system consisting of a packed column terminating at an FID. Analysis on the multi-column system began with cryogenic pre-concentration of sample at $400 \mathrm{~mm} \mathrm{Hg}$, followed by injection into 6 separate columns, contained in pairs in a combination of 3 ovens (Hewlett-Packard 6890 series GC system). Temperature ramp programs were set at $-60^{\circ} \mathrm{C}$ to $220^{\circ} \mathrm{C}$ for 2 ovens and $-20^{\circ} \mathrm{C}$ to $200^{\circ} \mathrm{C}$ for the third. This GC system utilized several detectors including FID, electron capture (ECD), and mass selective detectors (MSD). The combination of columns and detectors includes DB-1/FID (Agilent), PLOT+DB-1/FID (Agilent), Restek1701/ECD (Restek), DB-5+Restek1701/ECD (Agilent, Restek) and DB-5ms/MSD (Agilent), many of which quantify the same gases. The redundant gases for each column were plotted against one another, to ensure a linear trend. This elucidated chemical differences of any co-eluting peaks by comparison of different 
column results. Exhaled hydrogen sulfide $\left(\mathrm{H}_{2} \mathrm{~S}\right)$ or methanethiol (monomethylsulfide) was not quantified in this analysis.

\section{Chemokines and Cytokines}

The plasma cytokine response to IP ATP $(0.5 \mu \mathrm{mol} / \mathrm{g})$ or saline was examined at baseline, 30-minutes and 4hours after injection in 6-month old female C57BL/6J mice. Heparinized plasma was diluted 2-fold in saline and analyzed at the UCSD CTF-C Core Lab using the 7-plex MSD Multispot Assay system (Meso Scale Diagnostics, LLC, Gaithersburg, MD, USA) according to manufacturer instructions. The 7 cytokines examined and the lower limit of detection (LLOD in pg/ml) were: IL10 (11), CXCL1 (3.3), IL12p70 (35), IL1b (0.75), TNFa (0.85), IL6 (4.5), and IFNg (0.38).

\section{Corticosterone Assays}

Four-month old C57BL/ 6 females ( $\mathrm{N}=7$ per time point) were treated with $0.5 \mu \mathrm{g} / \mathrm{g}$ ATP IP or saline at time 0 . Blood samples were collected before, 30-minutes after, and 4-hours after treatment. Plasma concentrations of

corticosterone were measured by ${ }^{125} \mathrm{I}$ double antibody radioimmunoassay using $10 \mu \mathrm{l}$ of plasma diluted 1:200 with assay buffer (MP Biomedicals LLC, Orangeburg, NY). The intraassay coefficient of variation (CV) was $4 \%$ with an interassay CV of $7 \%$.

\section{Temperature Measurements}

A BAT-12 Microprobe digital thermometer and RET-3 mouse rectal probe (Physitemp Instruments, Clifton, New Jersey) were used to obtain a temperature precision of $+/-0.1 \mathrm{CC}$, taking care to minimize stress-induced hyperthermia, as previously described [3].

\section{Basal Metabolic Rate}

Food intake, oxygen consumption and locomotor activity were measured using the Comprehensive Lab Animal Monitoring System (CLAMS, Columbus) in 13-minute cycles over a 3-hour period after nucleotide injection. Each mouse was housed in individual CLAMS cages with ad libitum access to Teklad 8604 standard mouse chow and water. Oxygen consumption $\left(\mathrm{VO}_{2}\right)$ and carbon dioxide production rates $\left(\mathrm{VCO}_{2}\right)$ were used to calculate the respiratory exchange ratio $\left(\mathrm{RER}=\mathrm{VCO}_{2} / \mathrm{VO}_{2}\right)$.

\section{Behavior}

We developed a purinergic behavioral response scale (PBRS) to quantify the magnitude of the behavioral response to purines and pyrimidines. The PBRS was a 3-point (0-absent, 1-present, and 2-severe) severity scale that assessed 6 characteristics: 1) open field avoidance, 2) decreased exploratory behavior or locomotor activity, stillness, 3) imbalance/ataxia in a cage rim walk test, 4) piloerection, 5) rapid shallow breathing/panting, 6) shivering/rigors. The PBRS range was 0 (normal) to 12.

\section{Statistical Analysis}


Results are reported as mean \pm SD unless otherwise noted. Peak area under the curve (AUC) data from metabolomics were $\log _{2}$ transformed, scaled by control standard deviations, and the resulting z-scores analyzed by univariate non-parametric analysis by Mann-Whitney $U$ test, and parametric analysis of $\geq 3$ groups by ANOVA. Cytokine data were $\log _{2}$ transformed using the generalized log transformation formula glog $\log _{2}(y+1)$ to accommodate fractional concentrations between 0 and $1 \mathrm{pg} / \mathrm{ml}$. Simple Linear Regression was used to compare dose-dependent rates of temperature decline. Linear Mixed Models analysis was used for longitudinal time and temperature data. Metabolomic data were analyzed by multivariate partial least squares discriminant analysis (PLSDA). Post hoc correction for multiple hypothesis testing after ANOVA was done by Fisher's least significant difference method in MetaboAnalyst [49, 50]. The false discovery rate (FDR) method of Benjamini and Hochberg [51] was used for all other analyses. Bayesian false discovery rates were estimated using the Storey q value [52]. Metabolites with variable importance in projection (VIP) scores were determined by PLSDA. Significant metabolites were grouped into pathways and their VIP scores summed to determine the rank-ordered significance of each biochemical pathway. Random forest analysis [53] was used to rank metabolites for their ability to distinguish the different treatment groups using mean decrease in accuracy (MDA) scores. $k$-nearest neighbor ( $k$-NN) clustering was used to identify metabolite groups that contributed in different ways to the experimental groups [54]. $k$-NN clusters were ranked by the sum of the VIP scores $\geq 1.0$ and by positive MDA scores. Dendrograms were Euclidean using Ward clustering. Pearson and Spearman correlation and logistic multiple regression was used to identify metabolites most associated with acute ATP injection. Results were organized into biochemical pathways and visualized in Cytoscape version 3.4.0. Statistical methods were implemented in Stata (Stata/SE12.1, StataCorp, College Station, TX), Prism (Prism 8, GraphPad Software, La Jolla, CA), Python, or R.

\section{Results}

\section{Study Overview}

The overall design of this study is illustrated in Figure 1. Six different experimental techniques were used to characterize the response to acute ATP injection.

\section{Metabolomics}

\section{Overview at 30 minutes}

A total of 202 (50\%) of 401 metabolites measured were significantly changed by ATP injection in 30 minutes (Table S1-S5, Figure S1-S12). The rank order of metabolites that were most changed is illustrated in Figure 2A. These metabolites belonged to 37 different biochemical pathways (Figure 2BC, Table S3) and showed FDRs $<0.05$, VIP $\geq 0.9$, and t-test $p$ values $<0.05$ (Table S2). There was a generalized decrease in plasma amino acids. Methionine levels in particular were strongly decreased, dropping by 43\% (Table S2). All amino acidsboth essential and non-essential-were affected (Figure S3). The average decrease across the 19 amino acids measured was $-5.0 \pm 2.6$ (Z-score \pm SD; Table S2). Fifteen ceramides and a class of phospholipids enriched in lysosomal and exosomal membranes, bis(monoacylglycero)phosphates (BMP), were also decreased (Table S3, Figure S6). Phosphatidylinositol (PI) lipids were decreased. The polar head groups of the major phospholipids were increased. This included choline, phosphorylcholine, ethanolamine and myoinositol. 
Myoinositol, which is a phospholipid head group derived by PI lipid activation to inositol phosphates for calcium signaling and subsequent processing by phosphatases, was sharply increased by ATP injection. Other head groups like phosphorylcholine and ethanolamine were also increased. Phosphatidylethanolamine (PE) lipids were decreased, while their precursors phosphatidylserine (PS) lipids were increased. Several arachidonate-derived eicosanoids, including 5-HETE and 13S-HODE, and the endocannabinoid anandamide, were also increased (Figure S4,Table S2). Dopamine was strongly increased 30 minutes after ATP injection with a Z-score of +5.5 (Figure 2A, Table S2). Other striking effects of acute ATP injection included an increase in lactate, glycerol-3-phosphate, and pyrimidines like orotic acid, thymidine, and thymine. As expected, purine metabolites were strongly increased (Figure S2, Figure 2A-C, Figure S9). These included xanthosine, allantoin, inosine, hypoxanthine, xanthine, and uric acid. Allantoin is disproportionately increased compared to uric acid in the mouse because mice have an intact uricase gene, while primates do not [55]. Adenosine triphosphate (ATP) was rapidly metabolized and was not detectable in any of the plasma samples (Table S1; detection limit = $100 \mathrm{nM}$ in heparinized plasma, data not shown).

The top 2 of $10 k$-NN clusters at 30 minutes after ATP injection were responsible for $79 \%$ of the metabolic impact and contained 134 metabolites with VIP scores $\geq 1.0$, from 36 different metabolic pathways. Seventyone (71) metabolites were increased with a mean Z-score of $+3.2 \pm 1.8$ (mean \pm SD; cluster \#2, Table S5, Figure S4) and belonged to a superpathway that included purines but was comprised of 26 different biochemical pathways. Sixty-three (63) metabolites were decreased with a mean Z-score of $-3.4 \pm 2.0$, including 19 of 19 measured amino acids, (cluster \#1, Table S6, Figure S5) and belonged to a second superpathway comprised of an overlapping set of 26 different biochemical pathways (Tables S2-S5).

\section{Overview at 4 hours}

A total of $54(13 \%)$ of 401 metabolites measured were changed at 4 hours after ATP injection (Figure 2D-F, Tables S1, S6-S9, Figure S1-S12). After 4 hours of recovery, one of 8 animals had recovered sufficiently to be indistinguishable from controls by multivariate analysis, while most others had not recovered completely. This is seen graphically by the overlap of sample points and the $95 \%$ confidence limits shown in the 2D PLSDA plots (Figure 2G; blue and pink circles), and in the dendrograms that show a clean statistical separation of ATP- and saline-treated animals at 30 minutes, but an intermixed response after 4 hours (Figure $2 \mathrm{H}$ ). During subacute recovery measured 4 hours after eATP injection, phospholipids and sphingolipids, were decreased. Several bile acids like glycocholic and taurocholic acid remained decreased. Increased turnover of phospholipids was evidenced by an increase in the phospholipid head groups phosphorylcholine, ethanolamine, and myoinositol. Several markers of cellular oxidation were increased 4 hours after ATP injection. These included increased oxidized glutathione (GS-SG) and cystine (CysS-SCys), and increased markers of carnosine metabolism such as 1-methylhistidine and histidine. Changes in nitrogen metabolism were marked by increases in agmatine, homoarginine, and urea (Figure S4).

The top 3 of $10 k$-NN clusters at 4 hours after ATP injection were responsible for $88 \%$ of the metabolic impact and contained 45 metabolites with VIP scores $\geq 1.5$ that belonged to 27 different metabolic pathways (Table S9-S11). Thirty-two (32) metabolites in the top k-NN cluster were increased with a mean Z-score of $+2.2 \pm 0.7$ (mean \pm SD; cluster \#3, Table S10) and belonged to a superpathway comprised of 19 different biochemical 
pathways. The second two superpathways contained 13 metabolites that were decreased with a Z-score range of -2.0 to -2.7 and were made up of 7 biochemical pathways (clusters \#7 and \#8, Table S9, S11).

A heat map of the 30 most increased or decreased metabolites is shown in Figure 2l. The proportional effects of purinergic signaling on all the biochemical pathways measured at 30 minutes and 4 hours after injection are illustrated in the Cytoscape map in Figure S1. Quantitative changes in purines, amino acid, methylation, sulfur, polyamine, and nitrogen metabolism are illustrated in Figure S9. Principal components analysis showed that metabolomics explained $81.2 \%$ and $74.9 \%$ of the phenotypic variance in animals at 30 minutes and 4 hours after ATP injection, respectively (Figure S10).

\section{eATP and the microbiome}

Eleven products of microbiome metabolism increased 30 minutes after eATP injection (Figure S7). These included an increase in the cysteine precursor $\mathrm{O}$-acetylserine, the leucine precursor isopropylmalic acid, the carnitine metabolite trimethylamine-oxide (TMAO), the histamine metabolite imidazoleacetic acid, two phenylketones from microbial tyrosine metabolism, 4-hydroxyphenyllactic acid and 4-hydroxyphenylpyruvic acid, and the aryl hydrocarbon receptor-binding immunomodulatory molecule and tryptophan metabolite indoxyl-3-sulfate [56]. The mean Z-score for increased microbiome metabolites in the plasma was $+3.5 \pm 1.5$ (Table S2). Only two microbiome metabolites, butyrylcarnitine $(Z=-5.7)$ and vitamin $\mathrm{K} 2$ (menaquinone; $Z=$ -1.2) were decreased 30 minutes after ATP injection. Unsubstituted purine, thought to be a marker of purinerich food intake [57], was decreased $(Z=-5.2) 30 \mathrm{~min}$ after ATP. The significance of this is not yet understood. No microbiome metabolites were abnormal 4 hours after ATP injection, although glycocholic, taurocholic, and taurodeoxycholic bile acids remained low ( $\mathrm{Z}=-1.5 \pm 0.2$; Table $S 6)$.

\section{eATP and plasma vitamin concentrations}

A broad range of vitamins were acutely changed in the plasma 30 minutes after ATP injection (Figure S8). Thiamine (B1), niacin (B3), pyridoxic acid (B6), and choline were increased by a mean Z-score of $+3.4 \pm 1.6$ (Table S2). In contrast, the plasma intermediates and effectors of 1-carbon metabolism were decreased. These included serine, glycine, and trimethyl-glycine (betaine), with a mean Z-score of $-4.4 \pm 1.8$ (Table S2). Vitamin D3 (cholecalciferol) was also decreased (Z-score $=-1.5)$, although active 1,25-dihydroxy Vitamin D3 was unchanged (Table S2). Thiamine (B1), niacin (B3), and pyridoxic acid (B6) remained increased in the plasma 4 hours after eATP injection, with a mean Z-score of $+1.8 \pm 1.1$ (Table S6, Figure S8). Other vitamins and cofactors that were increased at 4 hours included 5-methyl tetrahydrofolic acid (mTHF), dimethylglycine, flavin adenine dinucleotide (FAD; B2), and L-carnitine with a mean Z-score of $+1.7 \pm 0.9$. No vitamins were decreased 4 hours after ATP injection (Table S6 and S9).

\section{Breathomics}

\section{Overview}

Accurate measurements of exhaled gases requires normalization for minute volumes using the rate of $\mathrm{CO}_{2}$ production [48]. We found that ATP injection stimulated the release of volatile organic molecules ranging from 1 to 5 carbons in length in the first 10 minutes (Figure $3 \mathrm{~A}-\mathrm{H}$ ). These included the three different 1-carbon 
species: carbon monoxide (CO), methanol, and methane. One 2-carbon, sulfur-containing volatile was increased by ATP injection: dimethylsulfide. The remaining volatiles that were produced by acute hyperpurinergia included acetaldehyde (C2), acetone (C3), butyraldehyde (C4), and isoprene (C5; Figure 3A-H).

\section{Chemokines and Cytokines}

Cytokines were measured at baseline, 30-minutes and 4-hours after ATP or saline injection to permit comparison of metabolomic and cytokine data at these time points. The chemokine CXCL1, also known as KC and GROa, was increased 2.8 times compared to saline injections ( $526 \pm 118 \mathrm{pg} / \mathrm{ml}$ vs $188 \pm 75 ; \mathrm{p}<0.0002$ ). CXCL1 binds the G-protein coupled receptor CXCR2 and facilitates the arrest of rolling neutrophils and monocytes at sites of inflammation [58]. The anti-inflammatory interleukin, IL10 was also increased (95 \pm 56 vs $36 \pm 12 ; p<0.04$ ) (Figure 3I-K). ATP was known to stimulate IL10 secretion from microglial cells in culture [59], but had not been studied in animals. By 4 hours, each of these had returned to baseline levels. IL6 trended toward being increased at 30-minutes but animal-to-animal variability in the saline controls limited a stronger statistical conclusion without a larger sample size (Figure $3 \mathrm{~K}$ ). IL 1b, TNFa, IFNg, and IL12p40 were measured but unchanged at 30 minutes and 4 hours after IP ATP injection (data not shown).

\section{eATP Effects on Corticosterone Release}

Previous studies have shown that adrenal corticoid synthesis and release are directly stimulated by purinergic signaling at the adrenal cortex, independent of ACTH [60]. We found that plasma corticosterone peaked 30 minutes after injection of ATP, then trended below baseline levels by 4 hours (Figure $3 \mathrm{~L}$ ). This pattern of response was consistent with acute stimulation of corticosterone release, followed by feedback inhibition of hypothalamic corticotropin releasing hormone $(\mathrm{CRH})$ and ACTH. CRH and ACTH levels were not measured in this study.

\section{eATP Effects on Body Temperature}

We tested several nucleotides for their hypometabolic effects at the high dose of $0.5 \mu \mathrm{mol} / \mathrm{g} \mathrm{IP}$ in both males and females (Figure 4AB, Figure S10). All adenine-containing purines (adenosine, AMP, ADP, and ATP) produced a decrease in rectal temperature with a nadir that was reached 30-60 minutes after injection and recovery by 120 minutes. This effect lasted longer when the dose was administered intravenously instead of IP (Figure 4C). The behavioral changes caused by ATP also lasted longer when given IV (Figure 4D). ADP was most potent at these high doses of $0.5 \mu \mathrm{mol} / \mathrm{g}$ IP in both males and females (Figure 4AB). We next evaluated the gender-specific potency of each purine under non-saturating doses of 0 to $0.20 \mu \mathrm{mol} / \mathrm{g}$ measured at 15 minutes to reflect the initial phase of the metabolic response. Under these conditions we found that females were about $70 \%$ more sensitive to the hypothermic effects of ATP, i.e., had a more rapid decrease in temperature (Figure 4E, Table 1), while males were more than twice (108\%) as sensitive to ADP (Figure 4F, Table 1). AMP and adenosine were equally potent in both males and females (Figure 4GH). We also examined the metabolic effects of several other purines and pyrimidines and cyclic nucleotides at equimolar doses of $0.5 \mu \mathrm{mol} / \mathrm{g}$ IP compared to saline and ATP (Figure S11). In males, only cAMP showed a hypometabolic effect similar to ATP. In females, both cAMP and GTP showed some activity, but both were less potent than ATP.

\section{eATP Effects on Behavior}

Page 10/33 
The behavioral effects of ATP injection were stereotyped and dose dependent. The purinergic behavioral response scale scored the change in 6 behavioral characteristics: open field avoidance, decreased exploratory behavior or locomotor activity, rapid shallow breathing or panting, shivering or rigors, piloerection, and imbalance or ataxia. The onset of behavioral changes after a high dose $(0.5 \mu \mathrm{mol} / \mathrm{g})$ of ATP IP occurred within 1- 2 minutes, peaked at 30 minutes, and resolved by 60 minutes of IP injection (Figure 4I). Normal movements and self-grooming behavior gradually reappeared after 45 - 60 minutes, but the abnormal behavioral features were prolonged after an intravenous (IV) dose of ATP (Figure 4D). When non-saturating, low doses of ATP were given IP (0.025 - $0.20 \square \mathrm{moles} / \mathrm{g}$; Figure $4 \mathrm{~J})$, and outcomes were measured in the linear initial phase 15 minutes after injection, significant gender differences were observed in the response to extracellular ATP (eATP injection). Males were $37 \% \pm 3 \%$ more sensitive to the behavioral effects produced by eATP than females (male behavioral response slope $b=37.1 \pm 1$; female $b=27.4 \pm 0.7 ; p<000.1$; Figure $4 \mathrm{~J}$, Table 1).

\section{eATP Effects on Whole Body Metabolism}

The effects of eATP injection on whole body metabolism and oxygen consumption were quantified in Comprehensive Lab Animal Monitoring System (CLAMS cages, Figure 4K-N) using indirect calorimetry. By 26 minutes after a dose of $0.5 \mu \mathrm{mol} / \mathrm{g}$ ATP, whole body oxygen consumption $\left(\mathrm{VO}_{2}\right)$ dropped by $74 \% \pm 6 \%(5,303$ to $1,382 \mathrm{ml} / \mathrm{kg} / \mathrm{hr}, \mathrm{p}<0.0001$; Figure $4 \mathrm{~K})$ and the rate of $\mathrm{CO}_{2}$ production $\left(\mathrm{VCO}_{2}\right)$ dropped by $76 \% \pm 18 \%(4323$ to $1034 \mathrm{ml} / \mathrm{kg} / \mathrm{hr}, \mathrm{p}<0.0001$; Figure $4 \mathrm{~L})$. The respiratory exchange ratio $\left(\mathrm{RER}=\mathrm{VO}_{2} / \mathrm{VCO}_{2}\right)$ shifted from $0.84 \pm$ 0.08 , reflecting a balanced usage of fat and carbohydrate to nearly complete dependence on fatty acids with an RER $=0.70 \pm 0.062, p<0.006$; Figure $4 \mathrm{M}$, Table 1 ). Locomotor activity declined in both saline and ATP injected animals when placed in the wire-bottomed CLAMS cages for analysis, but the ATP-injected animals were nearly motionless between 26-52 minutes (Figure 4N, Table 1).

\section{eATP Activates a Latent Metabolic Memory Response in the MIA Model of ASD}

\section{Acute temperature response}

In the MIA model, pregnant female mice are exposed to a simulated viral infection by injection with the toll-like receptor 3 (TLR3) agonist poly(IC). This produces offspring with neurodevelopmental abnormalities associated with both autism spectrum disorders [61] and schizophrenia [62]. We administered ATP or saline to adult MIA offspring of poly(IC)-treated females and wild-type control offspring from saline-treated dams. We used a lower dose of $0.05 \square \mathrm{moles} / \mathrm{g}$ in females compared to $0.2 \mu \mathrm{mol} / \mathrm{g}$ in males because of the increased sensitivity of females to the hypothermic effects of ATP. All animals were 8-9 months of age. This is the human biological age equivalent of 35-38 years of age (see Materials and Methods). When the male MIA animals were given $0.2 \mu \mathrm{mol} / \mathrm{g}$ ATP, they had a $3.6 \pm 0.3 \square \mathrm{C}$ mean decrease in temperature (Figure $5 \mathrm{~A}$ ). MIA females had a $2.5 \pm 0.3 \square \mathrm{C}$ mean reduction in temperature following the $0.05 \mu \mathrm{mol} / \mathrm{g}$ dose of ATP (Figure 5B). Control males and females showed a similar short-term hypothermic response to ATP injection (Figure 5AB, red squares).

\section{Subacute temperature response}


We next recorded the body temperatures in MIA animals over 5 days after a single injection of 0.2 [moles $/ \mathrm{g}$ ATP (Figure 5CD). Although both MIA and control groups had a similar acute response to ATP injection in the first hour, their subacute response over the next 5 days differed. ATP injection produced a significant rise in basal body temperature for days 1-3 after injection only in the MIA mice (gold triangles; $0.7 \pm 0.1^{\circ}$ in males, $p<$ $0.0001 ; 0.6 \pm 0.1^{\circ}$ in females, $\mathrm{p}<0.003$ ), and not the unprimed wild-type controls, or the MIA animals treated with saline (Figure 5CD, purple vs gold triangles). The core body temperature of the MIA mice then returned to baseline by 5 days after ATP injection.

\section{Month-long temperature response in MIA mice after poly(IC) challenge}

We next followed the basal body temperature in 8-month old MIA males and controls for 28 days after a postnatal dose of poly (IC) or saline (Figure 5E). This experiment unmasked a triphasic temperature response to poly(IC) in both the MIA and control animals: 1) An initial increase in temperature on day 1 after poly(IC) (red and gold squares), 2) a decrease in temperature on days 2-4 to below the pre-challenge baseline, 3) a return to baseline in control animals by 5 days (red squares), or a rebound increase of $0.8 \square \mathrm{C}$ that was sustained between 6 to 14 days $(36.3 \pm 0.5$ vs $35.5 \pm 0.2 ; p<0.0001)$ in the MIA animals challenged with poly (IC), with a gradual return to baseline only after 28 days (gold squares). Poly(IC) injection in both the MIA and control mice produced a similar magnitude of hypothermia on days 2 to 4 . Note that the MIA animals with ASD-like behaviors maintained a $0.5^{\circ} \mathrm{C}$ lower body temperature than saline-treated control animals before the challenge even at 8 months of age (Figure 5E, purple vs black circles to the left of the $y$-axis; Day 0 control temperature $=36.3 \pm 0.3^{\circ} \mathrm{C}$ vs poly $(\mathrm{IC})=35.8 \pm 0.4 ; 0.5^{\circ} \mathrm{C}$ difference, $\left.\mathrm{p}<0.03\right)$.

\section{Discussion}

Our studies showed that a relatively simple stimulus with a ubiquitous, but strictly compartmentalized metabolite, ATP, had a profound, multisystem effect on metabolism and behavior. Half of all metabolites measured (>200) were changed 30 minutes after ATP injection. Extracellular ATP is rapidly metabolized by cell surface ectonucleotidases CD73 and CD39 $[63,64]$ and other purine metabolic enzymes that include adenosine deaminase and purine nucleoside phosphorylase [65], AMP deaminase, IMP dehydrogenase, GMP synthase, and guanine deaminase [39]. Metabolism of ATP leads to the production of ADP, AMP, and adenosine, which can each bind different purinergic receptors, transporters, and other proteins, and lead to hypometabolism and can cause hypothermia by several different mechanisms [66]. Other purine metabolites like inosine, xanthosine, and xanthine are also produced. Xanthine is a source of superoxide and hydrogen peroxide through the action of the enzyme xanthine oxidase. Stress-induced increases in xanthine have recently been shown to cause anxiety-associated behaviors like the open field avoidance observed after ATP injection in this study. The mechanism was shown to be binding of xanthine to the adenosine A1 purinergic receptor in the amygdala [67]. The xanthine-anxiety effect is the complex outcome of mitochondrial fragmentation, and increased purine release from CD4+ T-cells under conditions of environmental stress. All the behavioral and the majority of metabolic effects of ATP injection reversed spontaneously within a few hours in the unprimed animals. However, there was an increased magnitude and duration of the response to postnatal eATP stimulation, or by CDR activation with poly (IC) in maternal immune activation (MIA) animals with ASD-like behaviors. 
The MIA model has been a classical laboratory model for ASD and schizophrenia for over 10 years [61, 68-70]. The MIA model is typically created by exposing pregnant females to a simulated viral infection using the double strand RNA poly(IC). This results in a 24-hour flu-like syndrome with mild fever and decreased appetite that resolves spontaneously. However, the offspring born after an MIA pregnancy have ASD-like features, activated brain microglia, and abnormalities in synapse structure for life [71]. Detailed systems analysis of the MIA model has shown that it recapitulates many of the behavioral [68], metabolic [4], immune, microbiome [72], and brain synaptic features $[3,73]$ of children with ASD. In the past, it was shown that toll-like receptor 3 (TLR3) signaling triggered by poly(IC) was important to induce IL6 and IL17, which in turn played key roles in placental and brain inflammatory signaling that preceded the onset of ASD-like behaviors [74]. In humans, significant immunologic challenge and/or inflammation leading to fever during pregnancy, similar to that produced by poly (IC) in mice, is also known to increase the risk of autism [75, 76] and schizophrenia [77]. Repeated exposures to febrile triggers during the second trimester are particularly harmful [76].

Recent work with the MIA model has shown that poly(IC) per se is not necessary. A final common path appears to be the activation of purinergic signaling and the cell danger response (CDR) [1-4]. Horváth, et al. showed that injection of ATP itself into pregnant females was sufficient to produce the post-natal cerebellar Purkinje cell drop out and life-long autism-like behaviors that were indistinguishable from the classical MIA model [73]. Extracellular ATP and its metabolite ADP are both classical purinergic agonists and classical damage-associated molecular patterns (DAMPs) that are released from cells in response to nearly every physical, microbial, inflammatory, chemical, or metabolic stress studied to date $[11,14,15,78]$. Other recent work has shown that mitochondria play a critical role in cellular adaptive response by serving as the substrate for metabolic memory [79]. Mitochondria are crucial in regulating innate immunity and cellular defense [80]. Our results show that gestational immune activation can produce a durable metabolic memory that alters innate immune responses in offspring well into adulthood, and perhaps for life. This raises the possibility that chronic reductions in basal body temperature that are seen clinically in some children with autism [81] might be a marker of a primed and persistent state of the cell danger response (CDR) that occurred as a result of past exposures to infectious, inflammatory, or other environmental stress that occurred during pregnancy or early child development.

\section{Hyperpurinergic hypometabolism and the biological clocks of development and aging}

Several hypometabolic states are known in biology. These include hibernation, and less familiar states known as torpor, estivation, diapause, dauer, and caloric restriction [82]. In each case, the cause of the hypometabolic phenotype involves a combination of environmental factors that operate on both genes and metabolism. These hypometabolic states appear to have evolved as a concerted multisystem mechanism to protect the organism from environmental danger. For example, in addition to producing hypometabolism [83], adenine nucleotides like AMP have been shown to protect animals from lethal radiation [84]. Hypometabolism creates a side-effect that disconnects and slows the internal biological clock of the individual compared to the external clock of time experienced by other individuals. In this way, biological time is relative to individualized physiology and is controlled by local organismal and tissue factors. In the case of dauer, the normal 2-week lifespan of the worm Caenorhabditis elegans, is extended for up to 4 months under conditions of environmental stress [85]. Development slows to nearly a stop during this time, as the rates of many biological reactions are slowed. The animal does not eat during dauer, so the chance of consuming 
something toxic from the environment is eliminated. When the conditions that created the environmental danger are removed, the worm reenters its normal life cycle as if no time had elapsed, even though 2-4 months of external time may have passed. At this point, the internal biological clock of development re-entrains with the external clock of the sun and seasons. The animals that emerge from dauer undergo rapid catch-up development to achieve reproductive maturity in a few days and eventually die at the usual developmental age in 1-2 weeks. Caloric restriction in vertebrates produces a similar slowing of the biological clock associated with aging $[27,86]$.

It is tempting to speculate that biological aging can be compartmentalized, such that different organ systems age at different rates in a way controlled by the compartmentalization of local stress and the associated release of ATP and other metabokines. For example, if cells in the brain experience stress, they would be expected to release ATP since all stressed cells release ATP and ADP $[87,88]$. Since the brain controls whole body metabolism through autonomic and neuroendocrine communication with all the organs, the function of many organ systems like the gut and immune system is affected by brain function. If the stress is transient, for example after the neuromuscular activity associated with exercise, then the associated purinergic signaling would contribute to a beneficial CNS adaptive response. If on the other hand, the stress and associated purinergic signaling were repetitive or chronic, they would activate a more persistent cell danger response, promote microglial activation, and lead to a slowing and alteration of developmental progress in children.

Compartmentalized danger signaling and metabolic slowing in a child could have a protective effect during neurodevelopment. The normal critical windows of readiness for child neurodevelopment might be prolonged because the internal biological clock of the brain has slowed, while the development of organ systems outside the brain might be less affected, or unaffected entirely because they are protected from brain eATP by the blood brain barrier. After the metabolic danger signals that have maintained the compartmentalized purinergic and metabokine signaling have been removed or restored to normal, the internal clock of a child's brain development can restart at a new speed. Experience with malnourished children and inborn errors of metabolism has shown that once a missing metabolic factor or calories are provided, or a metabolic or socioeconomic block removed [89, 90], catch-up development with symptom improvements can be rapid until a new steady state of child development is reached. The outcome of therapy is improved if it is instituted before age 5-10 [91, 92], but symptom improvement can also occur in adults affected by a genetic or neurometabolic block [93]. If this hypothesis is true for even a small fraction of children and adults with ASD, it means that new approaches to therapy, including antipurinergic therapies [4, 94], might fundamentally reset, restart, or improve brain developmental outcomes by normalizing the developmental clock of the brain, allowing it to resynchronize with the developmental clocks of other impacted organ systems like the gut, the microbiome, and immune systems.

\section{The heterogeneous pattern of metabolic recovery after ATP exposure}

The recovery from acute hyperpurinergia measured by metabolomics at 4 hours after ATP injection was characterized by greater inter-individual heterogeneity than the acute response at 30 minutes. Individual animals returned to the pre-injection ground state of metabolism in a less-stereotyped, more-individualized way, and by using biochemical pathways that were not simply the reversal of the acute changes. This

Page 14/33 
probabilistic exit from the cell danger response over time mirrored the non-deterministic cell-cycle re-entry of bacterial persister cells [95], and the transient arousals characterized by periodic rewarming and cooling of hibernating mammals throughout winter [96] until springtime has been firmly reestablished after a long period of harsh environmental conditions.

\section{Plasma amino acids}

One of the most striking metabolic effects of ATP injection was the generalized decrease in all measured plasma amino acids within 30 minutes of the hyperpurinergic stimulus. The average decrease across 19 of 19 measured amino acids was $-5.0 \pm 2.6$ standard deviations compared to saline controls. The pool of amino acids in the plasma is exchanged rapidly with tissues and is highly regulated [97]. It is currently unknown into which tissues the amino acids were transported in response to ATP signaling. If the uptake is selective into muscle, the resulting plasma depletion could trigger an amino acid depletion response in another tissue like liver. Such compartmentalization of the amino acid depletion response could lead to the accumulation of uncharged tRNAs and the activation of transcription factors like GCN2. GCN2 initiates a program of metabolic changes associated with the amino acid depletion response that stimulates autophagy and decreases inflammation and mammalian target of rapamycin complex 1 (mTORC1) signaling. Because protein synthesis imposes a significant energy cost on the cell, the amino acid response preserves ATP and GTP, and contributes to the hypometabolic response. GCN2 activation protects the cell from environmental danger [98, 99], and contributes to longevity [100], but at the cost of inhibited healing [27]. The role of extracellular ATP signaling in the GCN2-on/mTORC1-off mediated amino acid depletion response has not yet been investigated.

\section{Vitamins}

Vitamins are essential cofactors for enzymes that catalyze thousands of metabolic reactions in the cell. Without an adequate concentration of vitamins in cells, many metabolic reactions will slow or stop. Therefore, a concerted mechanism for rapidly changing the blood concentration of vitamins in response to environmental threat would have the effect of rapidly changing the flux of metabolites through all the biochemical pathways controlled by vitamin availability. Mitochondria are especially rich in enzymes requiring the B vitamins. Thiamine (B1), niacin (B3), pyridoxic acid (B6), FAD (B2), methyl-tetrahydrofolic acid (mTHF, B9), and carnitine were each increased in the plasma after ATP injection. In contrast, the vitamin D precursor cholecalciferol (vitamin D3) was decreased by ATP injection. The mobilization of vitamins and conditionallyessential nutrients like carnitine during stress may deplete intracellular pools in some organs in exchange for making them available in the plasma for other tissue types. For example, if a significant amount of FAD and niacin comes into the plasma from the liver and this is sustained for more than a few hours, then mitochondrial fatty acid oxidation, which requires FAD and NAD+ from niacin as cofactors, might be decreased and lead to abnormalities in plasma acyl-carnitines. We did not measure plasma metabolites for more than 4 hours after ATP injection. However, abnormalities in fatty acid oxidation and acyl-carnitine profiles in children with ASD are well known [101]. The effect of purinergic signaling on the redistribution of intracellular vitamin pools in different organs like the liver or muscle, and on excretion in the urine has not yet been investigated. 


\section{Microbiome}

Another surprising effect of ATP injection was the dramatic increase in metabolites known to be derived predominantly or entirely from microbial metabolism in the gut. Thirteen of 20 measured microbiome metabolites were changed and 11 of these were increased 30 minutes after ATP injection. We hypothesize that systemic exposure to ATP and ADP may increase intestinal permeability by regulating zonulin located in the tight junctions between intestinal epithelial cells and lead to the phenomenon known as a leaky gut [102]. One caveat to this interpretation is that the purinergic stimulus in this study was given by intraperitoneal injection, which transiently exposes the serosal surface of the intestines to higher concentrations of eATP before it is absorbed into the blood. This may amplify the effect of eATP on tight junctions. On the other hand, it has been shown that functional changes in mitochondria directly change the microbiome [103] and intestinal epithelial cell and mucosal function at the host-microbe interface [104]. The inhibition of mitochondrial function by systemic eATP shown in this study might therefore be a direct cause of intestinal epithelial cell functional changes that lead to chronic changes in the microbial ecology of the gut. The differential effects of IP vs IV ATP injection on microbiome metabolites and more direct measures of leaky gut have not yet been studied.

\section{Volatile Organic Compounds in the Breath}

Breathomics analysis showed that ATP injection stimulated an increase in several small volatile organic compounds (VOCs) from 1 to 5 carbons in length. The increase in one-carbon redox series carbon monoxide (CO), methanol, and methane supports the concept of a relative block in protein, lipid, nucleic acid, and polysaccharide (macromolecular polymer) synthesis. The CDR-mediated shift toward oxidizing conditions minimizes the chances that an invading microbe can usurp cellular resources for synthesizing its own polymers, and leads naturally to the accumulation of small molecular weight intermediates and monomers [10]. In addition, $\mathrm{CO}$ is produced naturally under stress conditions by heme oxygenase, which leads in turn to an increase in the biliary secretion of glutathione and bile acids [105]. This has been traced to the inhibitory effect of $\mathrm{CO}$ on the enzyme cystathionine b-synthase (CBS) and to the inhibition of $\mathrm{H}_{2} \mathrm{~S}$ synthesis by this enzyme [106]. This complex set of interactions may help explain the observation of persistent decrease in plasma bile acids measured 4 hours after ATP stimulation. Since the availability of microbiome-modified bile acids is necessary for binding to and regulating the anti-inflammatory effects of the farnesoid $X$ receptors (FXRs) [107], decreased bile acids can further contribute to the pro-inflammatory state of a persistently activated CDR. The decrease in biosynthetic enzymes and plasma bile acid concentration was corrected in the Fragile $X$ mouse model by treatment with the antipurinergic drug suramin [1]. We also found the 5-carbon isoprene to be elevated after ATP injection. Isoprene is a building block of cholesterol, steroid hormones, bile acids, and the electron carrier CoQ10. Other studies have measured isoprene in the breath of children and found it to be increased with steroid hormone synthesis in puberty [108], and in adults after exercise and even with the normal orthostatic stress of standing up after sitting or reclining [109].

\section{The Triphasic Response}

MIA animals showed a triphasic temperature response to the TLR3 activator and double strand RNA, poly(IC), that differed from the response in typically developing controls. There was an acute increase in temperature in 
the first day, followed by a hypothermic response from days 2-4, then a hyperthermic rebound that occurred at 5 days and lasted a month. This rebound to above the pre-challenge baseline temperature did not occur in control animals. It is well known in children with ASD that some autism-related behaviors improve from the period immediately preceding a recognized fever, and for the next few days throughout the period of fever. Once the fever remits, the symptoms of ASD return [110]. We did not test the ASD-related behaviors like social approach in the MIA animals in the hours and days following postnatal challenge with poly(IC). Future studies will be needed to quantify the ASD-like behaviors during each phase of the triphasic temperature response to generic innate immune triggers like ATP and poly(IC) to test the similarity to the human ASD fever response.

\section{Limitations}

Only one strain of mouse, the $\mathrm{C} 57 \mathrm{BI} / 6 \mathrm{~J}$ strain, was used in this study. Although this is the classic laboratory mouse strain used in the MIA model, other genetic backgrounds such as the FVB mouse used in our previous studies of Fragile X syndrome [1], could theoretically show different metabolic responses to ATP injection. However, the specific genetic differences between mouse strains, and even specific mutations leading to ASD, appear not to have a significant effect on purinergic signaling associated with ASD-like behaviors. Several groups have now shown that treatment with the antipurinergic drug suramin was able to correct all the behavioral abnormalities, and most of the metabolic abnormalities, in the MIA model in C57BI/6J mice, the Fragile X model in FVB mice [1-3], a rat model of ASD caused by prenatal exposure to valproic acid [111], and in a small clinical trial in children with ASD [4]. Metabolomic analysis after correction of the ASD-associated behaviors showed that the top metabolic pathway changed by treatment in all of these studies was purines [1, 2 , 4]. ATP injection in rats is also known to cause hypothermia and pro-inflammatory effects in the brain [112] but metabolomics have not yet been performed. Intravenous infusions of ATP have been reported in patients with advanced cancer [113]. However, none of the published studies in humans have reported body temperature or metabolomic responses before and after the IV infusion. Although a small human clinical trial of antipurinergic therapy in children with ASD supports the CDR hypothesis and the crucial importance of purinergic signaling [4], the generalizability of the current mouse studies to larger studies in children with ASD is unknown.

\section{Conclusions}

The cell danger response (CDR) is an evolutionarily conserved, multi-system response to environmental stress. The CDR redirects cellular energy resources and metabolic building blocks away from housekeeping functions to new functions for purposes of cellular defense. When this happens during pregnancy or persistently in early childhood, neurodevelopmental disorders can result. Our metabolomic results showed that many aspects of the acute CDR were reproduced experimentally in mice by the systemic injection of the classical purinergic agonist ATP. Acute hyperpurinergia produced a dramatic decrease in whole body oxygen consumption, metabolic rate and temperature, and produced major shifts in mitochondrial metabolism documented by changes in amino acid, fatty acid, nucleotide, phospholipid, bile acid, redox, microbiome, and energy metabolism. If the inflammation associated with P2X7 signaling can be avoided [114], these studies raise the possibility that the development of new pro-purinergic hypometabolic drugs (PPDs) may be able to produce a transient state of cellular hypometabolism and organ cooling that could have utility in the fields of transplant biology, military and motor vehicle trauma, kidney, heart, liver, and brain surgery, and space medicine. On the 
other hand, the development of new antipurinergic drugs (APDs) with suramin-like actions might prove therapeutic in clinical conditions characterized by persistent activation of the cell danger response such as autism [1, 2, 4], myalgic encephalomyelitis/chronic fatigue syndrome (ME/CFS) [115], Gulf War illness [116], post-traumatic stress disorder (PTSD), major depressive disorder (MDD) and bipolar disorder (BD) [117], amyotrophic lateral sclerosis (ALS) [118], and several other developmental, neurodegenerative, and agerelated disorders [10, 27].

ATP injection also produced acute behavioral changes that have been previously associated with anxiety in mouse models of ASD [119], and in response to environmental stress [67]. Abnormal behaviors included open field avoidance and a decrease in exploratory behaviors. We also noted transient ataxia. These behaviors and neurological signs have similarities to children with ASD. We found exaggerated and prolonged metabolic responses to danger signals like poly(IC) and extracellular ATP (eATP) in MIA animals with pre-existing ASDlike behaviors compared to typically developing controls. MIA animals were hypersensitive to these generic cell danger signals. In addition, we found that males were more sensitive to the behavioral effects of systemic eATP. Females were more sensitive to the metabolic effects of eATP reflected by increased changes in body temperature and metabolic rates. It is a common experimental observation to see fewer ASD-like behaviors in female mice compared to their male littermates in the MIA mouse model [3]. The greater sensitivity of females to the metabolic effects of ATP signaling may contribute to the 3 to 1 increased risk of females compared to males for another complex disorder, myalgic encephalomyelitis/chronic fatigue syndrome (ME/CFS) [120]. The increased behavioral response to ATP signaling and decreased metabolic response in males may contribute to the 4 to 1 increased risk of males compared to females for the development of ASD. The hypersensitivity to extracellular ATP or ADP and poly(IC) in animals with ASD-like behaviors in this study may be relevant for the persistent activation of the CDR by environmental stresses of many kinds known to change child development, including early life stress [26] and environmental pollution [29]. In children with ASD, the hypersensitivity to purinergic agonists and to other innate immune triggers like microbial infections that trigger ATP release, would mean that relatively small increases in extracellular ATP or ADP can produce dramatic behavioral and metabolic changes that can disrupt development and oppose therapeutic efforts.

\section{List Of Abbreviations}

Ado: adenosine. APT: antipurinergic therapy. APD: antipurinergic drugs. CDR: cell danger response. MIA: maternal immune activation. TLR3: toll-like receptor 3, PPD: Propurinergic drugs.

\section{Declarations}

\section{Competing Interests}

The authors declare that they have no competing interests.

\section{Declarations}

1. Ethics approval and consent to participate-not applicable

2. Consent for publication-not applicable 


\section{Funding}

This research was supported by the UCSD Christini Fund, William Wright Family Foundation, the Lennox Foundation, the JMS Fund, the N of One Foundation, the Westreich Foundation, the Kirbie and Katie Mano Family Foundation, the Brent Kaufman Family Foundation, the Malone Family Foundation, the Daniel and Kelly White Family, the Cannistraro Family Foundation, the UCSD Mitochondrial Research Fund, the Aloe Family Autism Research Fund, the Harb and Spilo families, and grassroots support from over 2000 individuals from around the world who have each provided gifts in the past year to support Naviaux Lab research. Funding for the mass spectrometers was provided by a gift from the Jane Botsford Johnson Foundation. ZZ was recipient of a Novice Researcher Award from the Gerber Foundation, and an NIH U54-supported North American Mitochondrial Disease Consortium (NAMDC) Fellowship. The funders had no role in the study design, data collection and analysis, decision to publish, where to publish, or preparation of the manuscript.

\section{Author Contributions}

ZZ helped design and conducted the experiments, analyzed the data, and wrote the paper. TN helped design, conducted experiments, and edited the manuscript. LW contributed to experimental design and coordination. TPL contributed to biochemical characterizations. JCN contributed to the behavioral studies and conducted the metabolomics. KL performed the metabolomics. $\mathrm{CMH}, \mathrm{SM}$, and DB performed the breathomics studies. JMM contributed to the statistical analysis and data visualization. RKN directed the study, designed the experiments, analyzed the data, and wrote the paper.

\section{Acknowledgements}

The authors thank Richard Haas and Will Alaynick for helpful comments. We thank Alan Turken and Richard Hauger for the plasma corticosterone radioimmunoassays.

\section{References}

1. Naviaux JC, Wang L, Li K, Bright AT, Alaynick WA, Williams KR, Powell SB, Naviaux RK: Antipurinergic therapy corrects the autism-like features in the Fragile X (Fmr1 knockout) mouse model.Mol Autism 2015, 6:1.

2. Naviaux JC, Schuchbauer MA, Li K, Wang L, Risbrough VB, Powell SB, Naviaux RK: Reversal of autism-like behaviors and metabolism in adult mice with single-dose antipurinergic therapy.Transl Psychiatry 2014, 4:e400.

3. Naviaux RK, Zolkipli-Cunningham Z, Nakayama T, Naviaux JC, Le T, Wang L, Schuchbauer M, Rogac M, Li Q, Dugan LL, Powell S: Antipurinergic Therapy Corrects the Autism-Like Features in the Poly(IC) Mouse Model.PLoS One 2013, 8:e57380.

4. Naviaux RK, Curtis B, Li K, Naviaux JC, Bright AT, Reiner GE, Westerfield M, Goh S, Alaynick WA, Wang L, et al: Low-dose suramin in autism spectrum disorder: a small, phase $\mathrm{I} / \mathrm{ll}$, randomized clinical trial.Ann Clin Transl Neurol 2017, 4:491-505. 
5. Burnstock G, Campbell G, Satchell D, Smythe A: Evidence that adenosine triphosphate or a related nucleotide is the transmitter substance released by non-adrenergic inhibitory nerves in the gut. $\mathrm{Br} J$ Pharmacol 1970, 40:668-688.

6. Burnstock G: Purine and purinergic receptors.Brain Neurosci Adv 2018, 2:2398212818817494.

7. Ledderose C, Liu K, Kondo Y, Slubowski CJ, Dertnig T, Denicolo S, Arbab M, Hubner J, Konrad K, Fakhari M, et al: Purinergic P2X4 receptors and mitochondrial ATP production regulate T cell migration.J Clin Invest 2018, 128:3583-3594.

8. Ledderose C, Bromberger S, Slubowski CJ, Sueyoshi K, Junger WG: Frontline Science: P2Y11 receptors support T cell activation by directing mitochondrial trafficking to the immune synapse.J Leukoc Biol 2020.

9. Burnstock G: Purinergic cotransmission.Exp Physiol 2009, 94:20-24.

10. Naviaux RK: Metabolic features of the cell danger response.Mitochondrion 2014, 16:7-17.

11. Burnstock G, Knight GE: Cell culture: complications due to mechanical release of ATP and activation of purinoceptors. Cell Tissue Res 2017.

12. Sakaki H, Tsukimoto M, Harada H, Moriyama Y, Kojima S: Autocrine regulation of macrophage activation via exocytosis of ATP and activation of P2Y11 receptor.PLoS One 2013, 8:e59778.

13. Michaletti A, Gioia M, Tarantino U, Zolla L: Effects of microgravity on osteoblast mitochondria: a proteomic and metabolomics profile.Sci Rep 2017, 7:15376.

14. Heil M, Land WG: Danger signals - damaged-self recognition across the tree of life.Front Plant Sci 2014, 5:578.

15. Pittman K, Kubes P: Damage-associated molecular patterns control neutrophil recruitment.J Innate Immun 2013, 5:315-323.

16. Costa RP, Mizusaki BE, Sjostrom PJ, van Rossum MC: Functional consequences of pre- and postsynaptic expression of synaptic plasticity.Philos Trans R Soc Lond B Biol Sci 2017, 372.

17. Picard M, McManus MJ, Gray JD, Nasca C, Moffat C, Kopinski PK, Seifert EL, McEwen BS, Wallace DC: Mitochondrial functions modulate neuroendocrine, metabolic, inflammatory, and transcriptional responses to acute psychological stress. Proc Natl Acad Sci U S A 2015, 112:E6614-6623.

18. Calabrese EJ: Hormesis: Path and Progression to Significance.Int J Mol Sci 2018, 19.

19. Davies KJ: Adaptive homeostasis.Mol Aspects Med 2016, 49:1-7.

20. Pakos-Zebrucka K, Koryga I, Mnich K, Ljujic M, Samali A, Gorman AM: The integrated stress response.EMBO Rep 2016, 17:1374-1395.

21. Nigam SK: What do drug transporters really do? Nat Rev Drug Discov 2015, 14:29-44.

22. Fuchs EJ, Matzinger P: Is cancer dangerous to the immune system? Semin Immunol 1996, 8:271-280.

23. Matzinger P: Tolerance, danger, and the extended family.Annu Rev Immuno/ 1994, 12:991-1045.

24. Silva JM, Wong A, Carelli V, Cortopassi GA: Inhibition of mitochondrial function induces an integrated stress response in oligodendroglia.Neurobiol Dis 2009, 34:357-365.

25. Khan NA, Nikkanen J, Yatsuga S, Jackson C, Wang L, Pradhan S, Kivela R, Pessia A, Velagapudi V, Suomalainen A: mTORC1 Regulates Mitochondrial Integrated Stress Response and Mitochondrial 
Myopathy Progression.Cell Metab 2017, 26:419-428 e415.

26. Cameron JL, Eagleson KL, Fox NA, Hensch TK, Levitt P: Social Origins of Developmental Risk for Mental and Physical Illness.J Neurosci 2017, 37:10783-10791.

27. Naviaux RK: Incomplete Healing as a Cause of Aging: The Role of Mitochondria and the Cell Danger Response.Biology (Basel) 2019, 8.

28. Naviaux RK: Metabolic features and regulation of the healing cycle-A new model for chronic disease pathogenesis and treatment.Mitochondrion 2019, 46:278-297.

29. Naviaux RK: Perspective: Cell danger response Biology-The new science that connects environmental health with mitochondria and the rising tide of chronic illness.Mitochondrion 2020, 51:40-45.

30. Wallace DC: Bioenergetics in human evolution and disease: implications for the origins of biological complexity and the missing genetic variation of common diseases.Philos Trans R Soc Lond B Biol Sci 2013, 368:20120267.

31. Wallace DC, Fan W: Energetics, epigenetics, mitochondrial genetics.Mitochondrion 2010, 10:12-31.

32. Naviaux RK, Le TP, Bedelbaeva K, Leferovich J, Gourevitch D, Sachadyn P, Zhang XM, Clark L, Heber-Katz E: Retained features of embryonic metabolism in the adult MRL mouse.Mol Genet Metab 2009, 96:133144.

33. Ginsberg MR, Rubin RA, Falcone T, Ting AH, Natowicz MR: Brain transcriptional and epigenetic associations with autism.PLoS One 2012, 7:e44736.

34. Gevi F, Zolla L, Gabriele S, Persico AM: Urinary metabolomics of young Italian autistic children supports abnormal tryptophan and purine metabolism.Mol Autism 2016, 7:47.

35. Howsmon DP, Vargason T, Rubin RA, Delhey L, Tippett M, Rose S, Bennuri SC, Slattery JC, Melnyk S, James SJ, et al: Multivariate techniques enable a biochemical classification of children with autism spectrum disorder versus typically-developing peers: A comparison and validation study.Bioeng Trans/ Med 2018, 3:156-165.

36. Howsmon DP, Kruger U, Melnyk S, James SJ, Hahn J: Classification and adaptive behavior prediction of children with autism spectrum disorder based upon multivariate data analysis of markers of oxidative stress and DNA methylation.PLoS Comput Biol 2017, 13:e1005385.

37. Nyhan WL, James JA, Teberg AJ, Sweetman L, Nelson LG: A new disorder of purine metabolism with behavioral manifestations.J Pediatr 1969, 74:20-27.

38. Becker MA, Smith PR, Taylor W, Mustafi R, Switzer RL: The genetic and functional basis of purine nucleotide feedback-resistant phosphoribosylpyrophosphate synthetase superactivity.J Clin Invest 1995, 96:2133-2141.

39. Micheli V, Camici M, Tozzi MG, Ipata PL, Sestini S, Bertelli M, Pompucci G: Neurological disorders of purine and pyrimidine metabolism.Curr Top Med Chem 2011, 11:923-947.

40. Graf WD, Marin-Garcia J, Gao HG, Pizzo S, Naviaux RK, Markusic D, Barshop BA, Courchesne E, Haas RH: Autism associated with the mitochondrial DNA G8363A transfer RNA(Lys) mutation.J Child Neuro/ 2000, 15:357-361.

41. Estes ML, McAllister AK: Maternal immune activation: Implications for neuropsychiatric disorders. Science 2016, 353:772-777. 
42. Minakova E, Warner BB: Maternal immune activation, central nervous system development and behavioral phenotypes.Birth Defects Res 2018, 110:1539-1550.

43. Solek CM, Farooqi N, Verly M, Lim TK, Ruthazer ES: Maternal immune activation in neurodevelopmental disorders.Dev Dyn 2018, 247:588-619.

44. Overton JM: Phenotyping small animals as models for the human metabolic syndrome: thermoneutrality matters.Int J Obes (Lond) 2010, 34 Suppl 2:S53-58.

45. Flurkey K, Currer, J.M., Harrison, D.E.: Mouse Models in Aging Research. In The Mouse in Biomedical Research, 2nd edition. Volume 3. Edited by Fox J. G. ea. San Diego, CA: Academic Press; 2007: 637-672.

46. Golde WT, Gollobin P, Rodriguez LL: A rapid, simple, and humane method for submandibular bleeding of mice using a lancet.Lab Anim (NY) 2005, 34:39-43.

47. Li K, Naviaux JC, Bright AT, Wang L, Naviaux RK: A robust, single-injection method for targeted, broadspectrum plasma metabolomics.Metabolomics 2017, 13:122.

48. Langeroudi AG, Hirsch CM, Estabragh AS, Meinardi S, Blake DR, Barbour AG: Elevated carbon monoxide to carbon dioxide ratio in the exhaled breath of mice treated with a single dose of lipopolysaccharide.Open Forum Infect Dis 2014, 1:ofu085.

49. Xia J, Sinelnikov IV, Han B, Wishart DS: MetaboAnalyst 3.0-making metabolomics more meaningful.Nucleic Acids Res 2015, 43:W251-W257.

50. Chong J, Soufan O, Li C, Caraus I, Li S, Bourque G, Wishart DS, Xia J: MetaboAnalyst 4.0: towards more transparent and integrative metabolomics analysis.Nucleic Acids Res 2018.

51. Benjamini $Y$, Hochberg Y: Controlling the false discovery rate-a practical and powerful approach to multiple testing.Journal of the Royal Statistical Society Series B-Methodological 1995, 57:289-300.

52. Storey JD: The positive false discovery rate: a Bayesian interpretation and the q-value. The Annals of Statistics 2003, 31:2013-2035.

53. Breiman L: Random Forests. Machine Learning 2001, 45:5-32.

54. Altman NS: An introduction to kernel and nearest-neighbor nonparametric regression. The American Statistician 1992, 46:175-185.

55. Kratzer JT, Lanaspa MA, Murphy MN, Cicerchi C, Graves CL, Tipton PA, Ortlund EA, Johnson RJ, Gaucher EA: Evolutionary history and metabolic insights of ancient mammalian uricases.Proc Natl Acad Sci U S A 2014, 111:3763-3768.

56. Ghimire S, Matos C, Caioni M, Weber D, Peter K, Holler E, Kreutz M, Renner K: Indoxyl 3-sulfate inhibits maturation and activation of human monocyte-derived dendritic cells./mmunobiology 2018, 223:239-245.

57. Kaneko K, Aoyagi Y, Fukuuchi T, Inazawa K, Yamaoka N: Total purine and purine base content of common foodstuffs for facilitating nutritional therapy for gout and hyperuricemia.Biol Pharm Bull 2014, 37:709721.

58. Ley K: Arrest chemokines.Microcirculation 2003, 10:289-295.

59. Seo DR, Kim SY, Kim KY, Lee HG, Moon JH, Lee JS, Lee SH, Kim SU, Lee YB: Cross talk between P2 purinergic receptors modulates extracellular ATP-mediated interleukin-10 production in rat microglial cells.Exp Mol Med 2008, 40:19-26. 
60. Nishi H, Arai H, Momiyama T: NCl-H295R, a human adrenal cortex-derived cell line, expresses purinergic receptors linked to $\mathrm{Ca}(2)(+)-$ mobilization/influx and cortisol secretion.PLoS One 2013, 8:e71022.

61. Patterson PH: Modeling autistic features in animals.Pediatr Res 2011, 69:34R-40R.

62. Bitanihirwe BK, Peleg-Raibstein D, Mouttet F, Feldon J, Meyer U: Late prenatal immune activation in mice leads to behavioral and neurochemical abnormalities relevant to the negative symptoms of schizophrenia.Neuropsychopharmacology 2010, 35:2462-2478.

63. Allard B, Longhi MS, Robson SC, Stagg J: The ectonucleotidases CD39 and CD73: Novel checkpoint inhibitor targets.Immunol Rev 2017, 276:121-144.

64. Antonioli L, Pacher P, Vizi ES, Hasko G: CD39 and CD73 in immunity and inflammation. Trends Mol Med 2013, 19:355-367.

65. Grunebaum E, Cohen A, Roifman CM: Recent advances in understanding and managing adenosine deaminase and purine nucleoside phosphorylase deficiencies.Curr Opin Allergy Clin Immunol 2013, 13:630-638.

66. Carlin JL, Jain S, Gizewski E, Wan TC, Tosh DK, Xiao C, Auchampach JA, Jacobson KA, Gavrilova O, Reitman ML: Hypothermia in mouse is caused by adenosine A1 and A3 receptor agonists and AMP via three distinct mechanisms.Neuropharmacology 2017, 114:101-113.

67. Fan KQ, Li YY, Wang HL, Mao XT, Guo JX, Wang F, Huang LJ, Li YN, Ma XY, Gao ZJ, et al: Stress-Induced Metabolic Disorder in Peripheral CD4(+) T Cells Leads to Anxiety-like Behavior.Cel/ 2019, 179:864-879 e819.

68. Malkova NV, Yu CZ, Hsiao EY, Moore MJ, Patterson PH: Maternal immune activation yields offspring displaying mouse versions of the three core symptoms of autism.Brain Behav Immun 2012, 26:607-616.

69. Shi L, Smith SE, Malkova N, Tse D, Su Y, Patterson PH: Activation of the maternal immune system alters cerebellar development in the offspring.Brain Behav Immun 2009, 23:116-123.

70. Meyer U, Feldon J, Schedlowski M, Yee BK: Immunological stress at the maternal-foetal interface: a link between neurodevelopment and adult psychopathology.Brain Behav Immun 2006, 20:378-388.

71. Giovanoli S, Weber-Stadlbauer U, Schedlowski M, Meyer U, Engler H: Prenatal immune activation causes hippocampal synaptic deficits in the absence of overt microglia anomalies.Brain Behav Immun 2016, 55:25-38.

72. Hsiao EY, McBride SW, Hsien S, Sharon G, Hyde ER, McCue T, Codelli JA, Chow J, Reisman SE, Petrosino JF, et al: Microbiota modulate behavioral and physiological abnormalities associated with neurodevelopmental disorders. Cell 2013, 155:1451-1463.

73. Horvath G, Otrokocsi L, Beko K, Baranyi M, Kittel A, Fritz-Ruenes PA, Sperlagh B: P2X7 Receptors Drive Poly(I:C) Induced Autism-like Behavior in Mice.J Neurosci 2019, 39:2542-2561.

74. Hsiao EY, McBride SW, Chow J, Mazmanian SK, Patterson PH: Modeling an autism risk factor in mice leads to permanent immune dysregulation.Proc Natl Acad Sci U S A 2012, 109:12776-12781.

75. Croen LA, Qian Y, Ashwood P, Zerbo O, Schendel D, Pinto-Martin J, Daniele Fallin M, Levy S, Schieve LA, Yeargin-Allsopp M, et al: Infection and Fever in Pregnancy and Autism Spectrum Disorders: Findings from the Study to Explore Early Development.Autism Res 2019, 12:1551-1561. 
76. Hornig M, Bresnahan MA, Che X, Schultz AF, Ukaigwe JE, Eddy ML, Hirtz D, Gunnes N, Lie KK, Magnus P, et al: Prenatal fever and autism risk.Mol Psychiatry 2018, 23:759-766.

77. Brown AS, Patterson PH: Maternal infection and schizophrenia: implications for prevention.Schizophr Bull 2011, 37:284-290.

78. Banoth B, Cassel SL: Mitochondria in innate immune signaling. Trans/ Res 2018, 202:52-68.

79. Cheikhi A, Wallace C, St Croix C, Cohen C, Tang WY, Wipf P, Benos PV, Ambrosio F, Barchowsky A: Mitochondria are a substrate of cellular memory.Free Radic Biol Med 2019, 130:528-541.

80. Bird L: Innate immunity: Linking mitochondria and microbes to inflammasomes.Nat Rev Immuno/ 2012 , $12: 229$.

81. Hill SD, Wagner EA, Shedlarski JG, Jr., Sears SP: Diurnal cortisol and temperature variation of normal and autistic children.Dev Psychobiol 1977, 10:579-583.

82. Wu CW, Storey KB: Life in the cold: links between mammalian hibernation and longevity.Biomol Concepts 2016, 7:41-52.

83. O'Brien WG, 3rd, Ling HS, Zhao Z, Lee CC: New insights on the regulation of the adenine nucleotide pool of erythrocytes in mouse models.PLoS One 2017, 12:e0180948.

84. Ghosh S, Indracanti N, Joshi J, Ray J, Indraganti PK: Pharmacologically induced reversible hypometabolic state mitigates radiation induced lethality in mice.Sci Rep 2017, 7:14900.

85. Hand SC, Denlinger DL, Podrabsky JE, Roy R: Mechanisms of animal diapause: recent developments from nematodes, crustaceans, insects, and fish.Am J Physiol Regul Integr Comp Physiol 2016, 310:R1193-1211.

86. Hoshino S, Kobayashi M, Higami Y: Mechanisms of the anti-aging and prolongevity effects of caloric restriction: evidence from studies of genetically modified animals.Aging (Albany NY) 2018, 10:2243-2251.

87. Wei L, Mousawi F, Li D, Roger S, Li J, Yang X, Jiang LH: Adenosine Triphosphate Release and P2 Receptor Signaling in Piezo1 Channel-Dependent Mechanoregulation.Front Pharmaco/2019, 10:1304.

88. Chatterjee C, Sparks DL: P2X receptors regulate adenosine diphosphate release from hepatic cells. Purinergic Signal 2014, 10:587-593.

89. Nelson CA, Fox NA, Zeanah CH: Romania's abandoned children: deprivation, brain development, and the struggle for recovery. Cambridge, MA: Harvard University Press; 2014.

90. Hakman M, Chaffin M, Funderburk B, Silovsky JF: Change trajectories for parent-child interaction sequences during parent-child interaction therapy for child physical abuse.Child Abuse Negl2009, 33:461-470.

91. Jesson J, Koumakpai S, Diagne NR, Amorissani-Folquet M, Koueta F, Aka A, Lawson-Evi K, Dicko F, Kouakou K, Pety T, et al: Effect of Age at Antiretroviral Therapy Initiation on Catch-up Growth Within the First 24 Months Among HIV-infected Children in the leDEA West African Pediatric Cohort.Pediatr Infect Dis J 2015, 34:e159-168.

92. Lelijveld N, Seal A, Wells JC, Kirkby J, Opondo C, Chimwezi E, Bunn J, Bandsma R, Heyderman RS, Nyirenda MJ, Kerac M: Chronic disease outcomes after severe acute malnutrition in Malawian children (ChroSAM): a cohort study.Lancet Glob Health 2016, 4:e654-662. 
93. Trefz F, Maillot F, Motzfeldt K, Schwarz M: Adult phenylketonuria outcome and management.Mol Genet Metab 2011, 104 Suppl:S26-30.

94. Naviaux RK: Antipurinergic therapy for autism-An in-depth review.Mitochondrion 2018, 43:1-15.

95. Bhattacharjee A, Datta R, Gratton E, Hochbaum Al: Metabolic fingerprinting of bacteria by fluorescence lifetime imaging microscopy.Sci Rep 2017, 7:3743.

96. Brown JC, Chung DJ, Belgrave KR, Staples JF: Mitochondrial metabolic suppression and reactive oxygen species production in liver and skeletal muscle of hibernating thirteen-lined ground squirrels. Am J Physiol Regul Integr Comp Physiol 2012, 302:R15-28.

97. Makrides V, Camargo SM, Verrey F: Transport of amino acids in the kidney.Compr Physiol 2014, 4:367403.

98. Kim Y, Sundrud MS, Zhou C, Edenius M, Zocco D, Powers K, Zhang M, Mazitschek R, Rao A, Yeo CY, et al: Aminoacyl-tRNA synthetase inhibition activates a pathway that branches from the canonical amino acid response in mammalian cells. Proc Natl Acad Sci U S A 2020, 117:8900-8911.

99. Peng W, Robertson L, Gallinetti J, Mejia P, Vose S, Charlip A, Chu T, Mitchell JR: Surgical stress resistance induced by single amino acid deprivation requires Gcn2 in mice.Sci Trans/ Med 2012, 4:118ra111.

100. Barcena C, Quiros PM, Durand S, Mayoral P, Rodriguez F, Caravia XM, Marino G, Garabaya C, FernandezGarcia MT, Kroemer G, et al: Methionine Restriction Extends Lifespan in Progeroid Mice and Alters Lipid and Bile Acid Metabolism.Cell Rep 2018, 24:2392-2403.

101. Frye RE, Melnyk S, Macfabe DF: Unique acyl-carnitine profiles are potential biomarkers for acquired mitochondrial disease in autism spectrum disorder.Trans/ Psychiatry 2013, 3:e220.

102. Fasano $A$ : Zonulin and its regulation of intestinal barrier function: the biological door to inflammation, autoimmunity, and cancer.Physiol Rev 2011, 91:151-175.

103. Yardeni T, Tanes CE, Bittinger K, Mattei LM, Schaefer PM, Singh LN, Wu GD, Murdock DG, Wallace DC: Host mitochondria influence gut microbiome diversity: A role for ROS.Sci Signal 2019, 12.

104. McKay DM, Mancini NL, Shearer J, Shutt T: Perturbed mitochondrial dynamics, an emerging aspect of epithelial-microbe interactions.Am J Physiol Gastrointest Liver Physiol 2020, 318:G748-G762.

105. Norimizu S, Kudo A, Kajimura M, Ishikawa K, Taniai H, Yamaguchi T, Fujii K, Arii S, Nimura Y, Suematsu M: Carbon monoxide stimulates mrp2-dependent excretion of bilirubin-IXalpha into bile in the perfused rat liver.Antioxid Redox Signal 2003, 5:449-456.

106. Kabe Y, Yamamoto T, Kajimura M, Sugiura Y, Koike I, Ohmura M, Nakamura T, Tokumoto Y, Tsugawa H, Handa H, et al: Cystathionine beta-synthase and PGRMC1 as CO sensors.Free Radic Biol Med 2016, 99:333-344.

107. Fiorucci S, Baldoni M, Ricci P, Zampella A, Distrutti E, Biagioli M: Bile acid-activated receptors and the regulation of macrophages function in metabolic disorders. Curr Opin Pharmacol 2020, 53:45-54.

108. Smith D, Spanel P, Enderby B, Lenney W, Turner C, Davies SJ: Isoprene levels in the exhaled breath of 200 healthy pupils within the age range 7-18 years studied using SIFT-MS.J Breath Res 2010, 4:017101.

109. Karl T, Prazeller P, Mayr D, Jordan A, Rieder J, Fall R, Lindinger W: Human breath isoprene and its relation to blood cholesterol levels: new measurements and modeling.J Appl Physiol (1985) 2001, 91:762-770. 
110. Curran LK, Newschaffer CJ, Lee LC, Crawford SO, Johnston MV, Zimmerman AW: Behaviors associated with fever in children with autism spectrum disorders.Pediatrics 2007, 120:e1386-1392.

111. Hirsch MM, Deckmann I, Santos-Terra J, Staevie GZ, Fontes-Dutra M, Carello-Collar G, Korbes-Rockenbach M, Brum Schwingel G, Bauer-Negrini G, Rabelo B, et al: Effects of single-dose antipurinergic therapy on behavioral and molecular alterations in the valproic acid-induced animal model of autism.Neuropharmacology 2020:107930.

112. Zhang M, Li W, Niu G, Leak RK, Chen J, Zhang F: ATP induces mild hypothermia in rats but has a strikingly detrimental impact on focal cerebral ischemia.J Cereb Blood Flow Metab 2013, 33.

113. Beijer S, Hupperets PS, van den Borne BE, Wijckmans NE, Spreeuwenberg C, van den Brandt PA, Dagnelie PC: Randomized clinical trial on the effects of adenosine 5'-triphosphate infusions on quality of life, functional status, and fatigue in preterminal cancer patients.J Pain Symptom Manage 2010, 40:520-530.

114. Calzaferri F, Ruiz-Ruiz C, de Diego AMG, de Pascual R, Mendez-Lopez I, Cano-Abad MF, Maneu V, de Los Rios C, Gandia L, Garcia AG: The purinergic P2X7 receptor as a potential drug target to combat neuroinflammation in neurodegenerative diseases.Med Res Rev 2020.

115. Naviaux RK, Naviaux JC, Li K, Bright AT, Alaynick WA, Wang L, Baxter A, Nathan N, Anderson W, Gordon E: Metabolic features of chronic fatigue syndrome.Proc Natl Acad Sci U S A 2016, 113:E5472-5480.

116. Naviaux RK, Naviaux JC, Li K, Wang L, Monk JM, Bright AT, Koslik HJ, Ritchie JB, Golomb BA: Metabolic features of Gulf War illness.PLoS One 2019, 14:e0219531.

117. Illes P, Verkhratsky A, Tang Y: Pathological ATPergic Signaling in Major Depression and Bipolar Disorder.Front Mol Neurosci 2019, 12:331.

118. Illes P, Rubini P, Ulrich H, Zhao Y, Tang Y: Regulation of Microglial Functions by Purinergic Mechanisms in the Healthy and Diseased CNS.Cells 2020, 9.

119. Drapeau E, Riad M, Kajiwara Y, Buxbaum JD: Behavioral Phenotyping of an Improved Mouse Model of Phelan-McDermid Syndrome with a Complete Deletion of the Shank3 Gene.eNeuro 2018, 5.

120. Bakken IJ, Tveito K, Gunnes N, Ghaderi S, Stoltenberg C, Trogstad L, Haberg SE, Magnus P: Two age peaks in the incidence of chronic fatigue syndrome/myalgic encephalomyelitis: a population-based registry study from Norway 2008-2012.BMC Med 2014, 12:167.

\section{Tables}


Table 1

Metabolic and behavioral features of acute hyperpurinergia

\begin{tabular}{|c|c|c|c|c|c|c|c|c|}
\hline Phenotype & $\begin{array}{l}\text { Parameter } \\
\text { (26-30 min } \\
\text { post- } \\
\text { infusion) }\end{array}$ & $\begin{array}{l}\text { Saline } \\
\text { Response } \\
\text { (mean) }\end{array}$ & SD & $\begin{array}{l}\text { ATP } \\
\text { Response } \\
\text { (mean) }\end{array}$ & SD & Change & $\begin{array}{l}\text { Animals } \\
\text { Per } \\
\text { Group }\end{array}$ & $p$ value \\
\hline \multirow[t]{5}{*}{ Metabolic ${ }^{1}$} & $\begin{array}{l}\text { Oxygen } \\
\text { consumption } \\
\left(\mathrm{VO}_{2}\right. \\
\mathrm{ml} / \mathrm{kg} / \mathrm{hr})\end{array}$ & 5302 & 710 & 1382 & 325 & $-74 \%$ & 6 & 0.0001 \\
\hline & $\begin{array}{l}\mathrm{CO}_{2} \\
\text { production } \\
\left(\mathrm{VCO}_{2}\right. \\
\mathrm{ml} / \mathrm{kg} / \mathrm{hr})\end{array}$ & 4324 & 647 & 1034 & 226 & $-76 \%$ & 6 & 0.0001 \\
\hline & $\begin{array}{l}\text { RER } \\
\left(\mathrm{VCO}_{2} / \mathrm{VO}_{2}\right)^{2}\end{array}$ & 0.84 & 0.082 & 0.70 & 0.062 & -0.14 & 6 & 0.006 \\
\hline & $\begin{array}{l}\text { Radiated } \\
\text { heat } \\
\text { (cal/hour) }\end{array}$ & 650 & 84 & 180 & 40 & $-72 \%$ & 6 & 0.0001 \\
\hline & $\begin{array}{l}\text { Locomotor } \\
\text { activity (xyz } \\
\text { photobeam } \\
\text { breaks) }\end{array}$ & 742 & 442 & 27 & 16 & $-96 \%$ & 6 & 0.006 \\
\hline \multirow[t]{4}{*}{ Core Temp } & Males $\left({ }^{\circ} \mathrm{C}\right)^{3}$ & 37.9 & 0.38 & 34.3 & 0.99 & $-3.6^{\circ} \mathrm{C}$ & 6 & 0.0005 \\
\hline & $\begin{array}{l}\text { Females } \\
\left({ }^{\circ} \mathrm{C}\right)^{3}\end{array}$ & 38.4 & 0.13 & 32.2 & 0.26 & $-6.2^{\circ} \mathrm{C}$ & 6 & 0.0001 \\
\hline & $\begin{array}{l}\text { Male dose } \\
\text { response }(\beta \\
={ }^{\circ} \mathrm{C} / \mu \mathrm{mol} / \mathrm{g} \\
\text { ATP })^{4}\end{array}$ & 0 & 0 & -16.5 & 1.0 & $\mathrm{n} / \mathrm{a}$ & 6 & $0.0005^{4}$ \\
\hline & $\begin{array}{l}\text { Female dose } \\
\text { response }(\beta \\
=^{\circ} \mathrm{C} / \mu \mathrm{mol} / \mathrm{g} \\
\mathrm{ATP}^{4}\end{array}$ & 0 & 0 & -27.8 & 3.4 & $\mathrm{n} / \mathrm{a}$ & 6 & - \\
\hline
\end{tabular}

\footnotetext{
${ }^{1}$ ATP Dose $=0.5 \mu \mathrm{mol} / \mathrm{g} \mathrm{IP} \mathrm{C57BL} / 6 \mathrm{~J}$ females, 28 weeks old in CLAMS cages. ${ }^{2}$ Maximum change in RER was not reached for 52 minutes. ${ }^{3}$ Rectal temperature. 20-week old C57BL/6J. Cage temperature $=22.4^{\circ} \mathrm{C}$, ATP dose $=0.5 \mu \mathrm{mol} / \mathrm{g} \mathrm{IP}$. Males reached maximum hypothermia at 30 minutes, and females reached maximum at 45 minutes after injection. ${ }^{4}$ Linear regression analysis comparing the slopes $(\beta)$ for males and females: $F(1,53)=13.6, p<0.0005 .{ }^{5}$ Purinergic Behavioral Response Scale (PBRS). ${ }^{6}$ Linear regression analysis scored at 15 minutes, comparing the slopes $(\beta)$ for males and females: $F(1,52)=63.85, p<$ 0.0001 .
} 


\begin{tabular}{|c|c|c|c|c|c|c|c|c|}
\hline Phenotype & $\begin{array}{l}\text { Parameter } \\
(26-30 \text { min } \\
\text { post- } \\
\text { infusion) }\end{array}$ & $\begin{array}{l}\text { Saline } \\
\text { Response } \\
\text { (mean) }\end{array}$ & SD & $\begin{array}{l}\text { ATP } \\
\text { Response } \\
\text { (mean) }\end{array}$ & SD & Change & $\begin{array}{l}\text { Animals } \\
\text { Per } \\
\text { Group }\end{array}$ & $p$ value \\
\hline \multirow[t]{4}{*}{ Behavior $^{5}$} & $\begin{array}{l}\text { Males, } \\
\text { maximal } \\
\text { response } \\
\text { (after } \\
0.5 \mu \mathrm{mol} / \mathrm{g} \text { ) }\end{array}$ & 0 & 0 & 9.7 & 0.48 & $\mathrm{n} / \mathrm{a}$ & 10 & 0.0001 \\
\hline & $\begin{array}{l}\text { Females, } \\
\text { max } \\
\text { response } \\
\text { (after } \\
0.5 \mu \mathrm{mol} / \mathrm{g} \text { ) }\end{array}$ & 0 & 0 & 10.7 & 0.48 & $\mathrm{n} / \mathrm{a}$ & 10 & 0.0001 \\
\hline & $\begin{array}{l}\text { Male dose } \\
\text { response }(\beta \\
=\text { PBRS/ } \\
\mu \mathrm{mol} / \mathrm{g} \\
\text { ATP })^{6}\end{array}$ & 0 & 0 & 37.1 & 1.0 & $\mathrm{n} / \mathrm{a}$ & 6 & $0.0001^{6}$ \\
\hline & $\begin{array}{l}\text { Female dose } \\
\text { response }(\beta \\
=\text { PBRS/ } \\
\mu \text { mol/g } \\
\text { ATP })^{6}\end{array}$ & 0 & 0 & 27.4 & 0.7 & $\mathrm{n} / \mathrm{a}$ & 6 & - \\
\hline \multicolumn{9}{|c|}{$\begin{array}{l}{ }^{1} \text { ATP Dose }=0.5 \mu \mathrm{mol} / \mathrm{g} \text { IP C57BL/6J females, } 28 \text { weeks old in CLAMS cages. }{ }^{2} \text { Maximum change in RER } \\
\text { was not reached for } 52 \text { minutes. }{ }^{3} \text { Rectal temperature. } 20 \text {-week old } \mathrm{C} 57 \mathrm{BL} / 6 \mathrm{~J} \text {. Cage temperature }=22.4^{\circ} \mathrm{C} \text {, } \\
\text { ATP dose }=0.5 \mu \mathrm{mol} / \mathrm{g} \text { IP. Males reached maximum hypothermia at } 30 \text { minutes, and females reached } \\
\text { maximum at } 45 \text { minutes after injection. }{ }^{4} \text { Linear regression analysis comparing the slopes }(\beta) \text { for males } \\
\text { and females: } \mathrm{F}(1,53)=13.6, \mathrm{p}<0.0005 .{ }^{5} \text { Purinergic Behavioral Response Scale }(\mathrm{PBRS}) \text {. }{ }^{6} \text { Linear regression } \\
\text { analysis scored at } 15 \text { minutes, comparing the slopes }(\beta) \text { for males and females: } \mathrm{F}(1,52)=63.85, \mathrm{p}< \\
0.0001\end{array}$} \\
\hline
\end{tabular}

Figures 


\section{Figure 1}

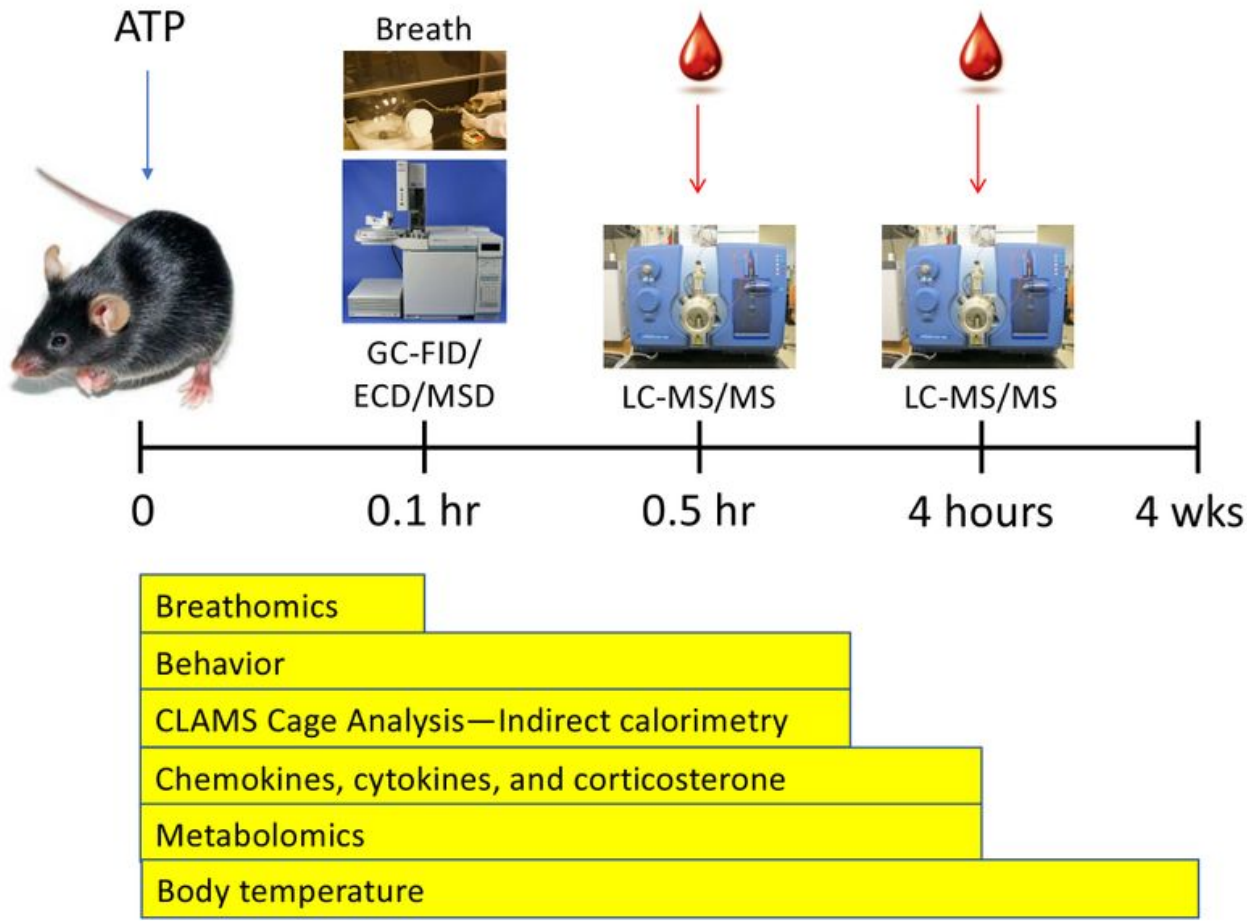

Figure 1

Study Overview. Abbreviations: GC-gas chromatography, FID-flame ionization detection, ECD-electron capture detection, MSD - mass selective detection, LC-high performance liquid chromatography, MS/MStriple quadrupole mass spectrometry. 


\section{Figure 2AB. 30 minutes}
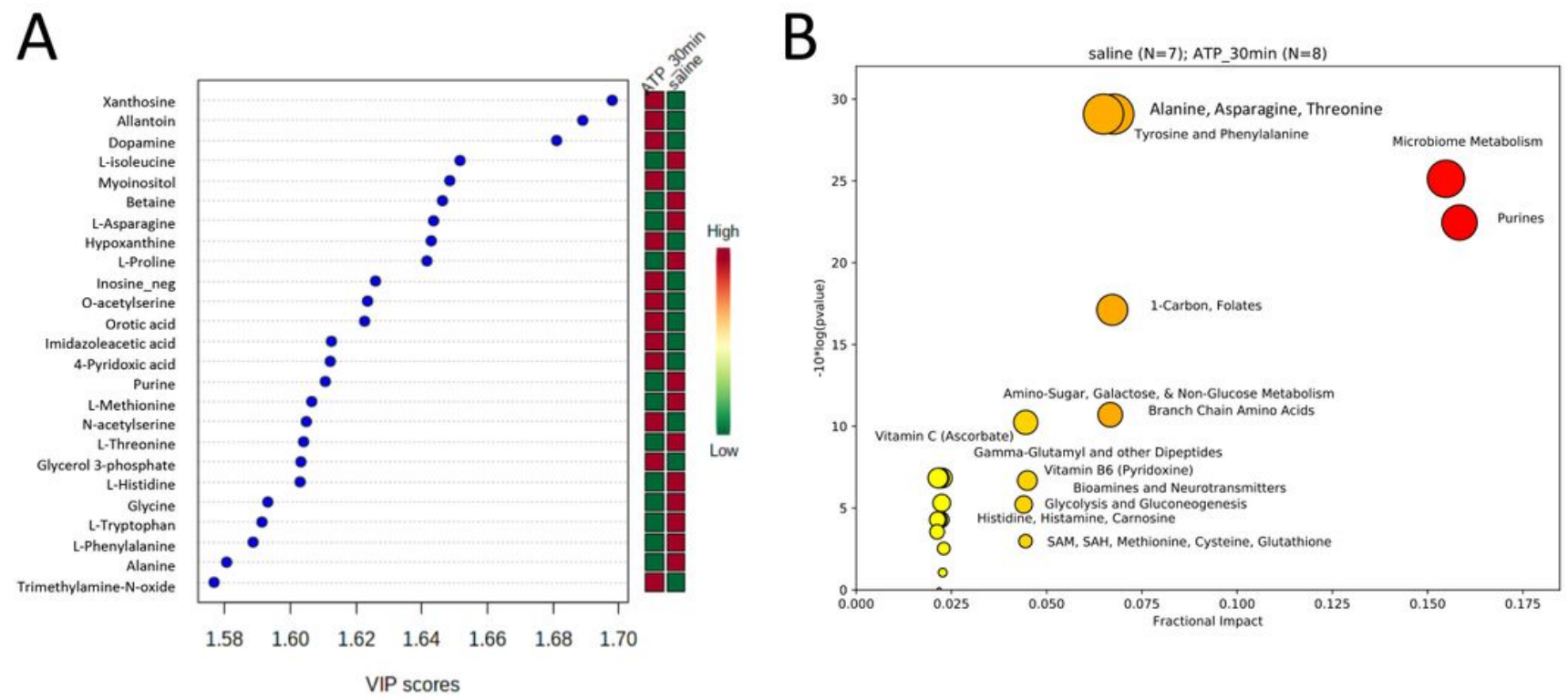

\section{Figure 2}

Metabolomic Analysis of Acute Hyperpurinergia. A. Ranking of metabolites changed 30 minutes after ATP injection by partial least squares discriminant analysis (PLSDA). B. Bubble impact plot of pathways most changed 30 minutes after ATP injection, $C$. Venn diagram of pathways increased, decreased, or contained increased and decreased metabolites after 30 minutes, D. Ranking of metabolites changed 4 hours after ATP injection by partial least squares discriminant analysis (PLSDA), E. Bubble impact plot of pathways most changed 4 hours after ATP injection, F. Venn diagram of pathways increased, decreased, or contained increased and decreased metabolites after 4 hours, G. Two-dimensional separation of the metabolomes by multivariate PLSDA components after saline and 0.5 and 4 hours post ATP injection, $\mathrm{H}$. Dendrogram showing sharp separation of the metabolome at 30 minutes and the heterogeneous and incomplete return to baseline by 4 hours after ATP injection, I. Heatmap of the top 30 most-changed metabolites 30 minutes and 4 hours after ATP injection. ATP dose $=0.5 \mu \mathrm{mol} / \mathrm{g}$ body weight, $\mathrm{n}=7-8 \mathrm{C} 57 \mathrm{BL} / 6 \mathrm{~J}$ males per group, age $=12-13$ weeks. Abbreviations: VIP-variable importance in projection. 


\section{Figure 3A-H. Breathomics}
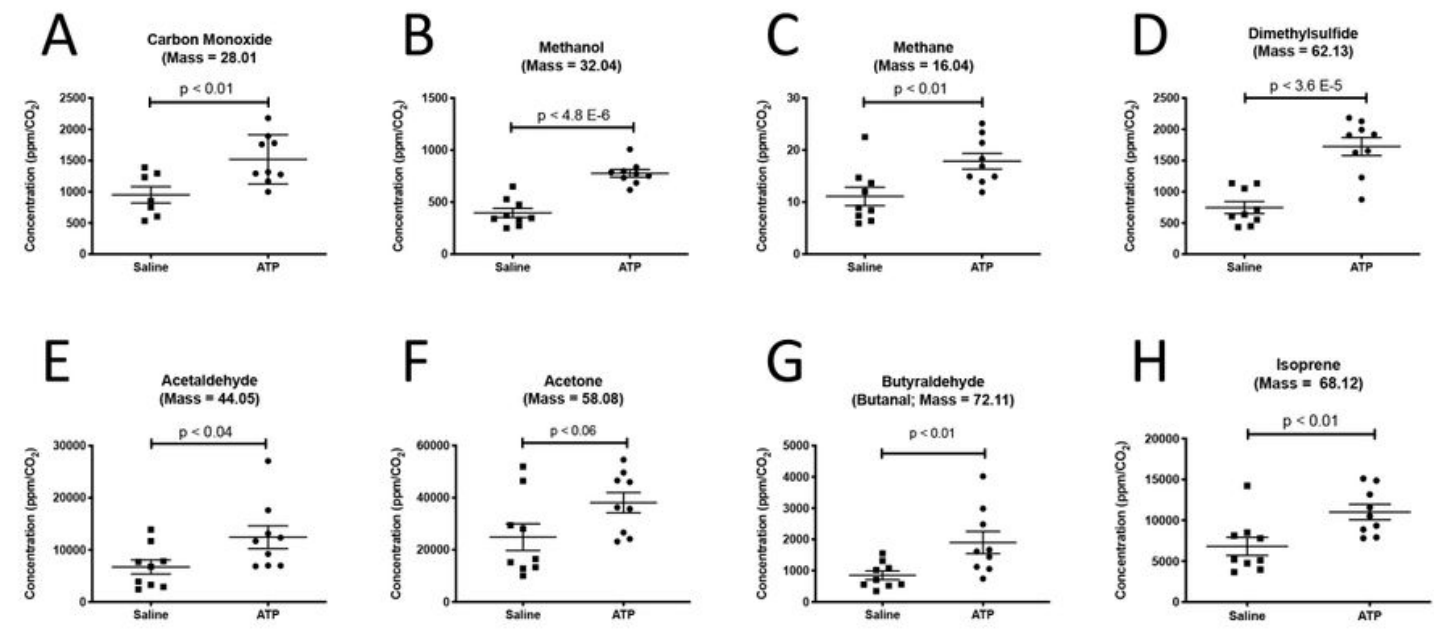

\section{Figure 3}

Breathomics, Chemokines, Cytokines, and Corticosterone Response to Acute Hyperpurinergia. Breathomics captured and analyzed exhaled breath at 1-10 minutes after ATP injection ( $\mathrm{A}-\mathrm{H} ; \mathrm{n}=3 \mathrm{C} 57 \mathrm{BL} / 6 \mathrm{~J}$ males per group, 3 samples per animal), A. Carbon monoxide, B. Methanol, C. Methane, D. Dimethylsulfide, E.

Acetaldehyde, F. Acetone, G. Butyraldehyde, H. Isoprene. Plasma chemokine and cytokine analysis $30 \mathrm{~min}$ and 4 hours after ATP injection (I-K; $\mathrm{n}=6-7 \mathrm{C57BL} / 6 \mathrm{~J}$ males per group), I. CXCL1/KC/GRO J. IL10, K. IL6. Plasma corticosterone levels 30 minutes and 4 hours after ATP injection (ATP dose $=0.5 \mu \mathrm{mol} / \mathrm{g}$ body weight, $\mathrm{n}=7$ C57BL/6J females per group), L. Corticosterone. Abbreviations: CXCL1-chemokine (C-X-C motif) ligand 1, KC -keratinocyte-derived chemokine, GRO-growth related oncogene alpha, IL10-interleukin 10, IL6-interleukin 6. 


\section{Figure 4AB. Temperature}

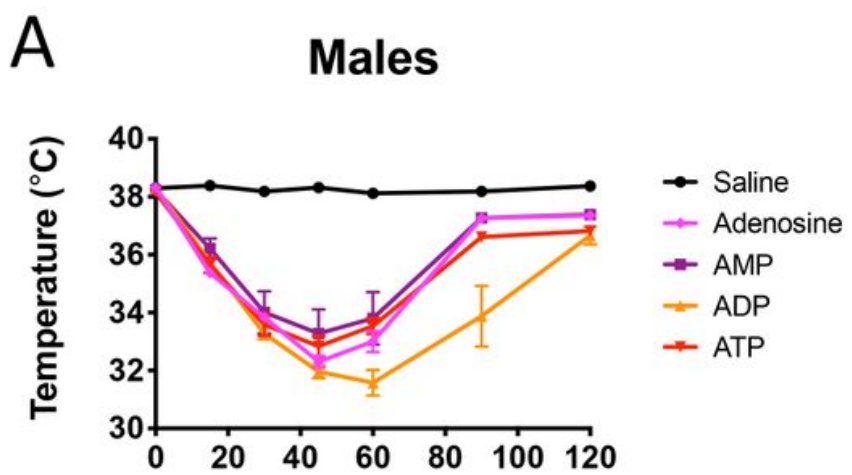

Minutes post injection
B Females

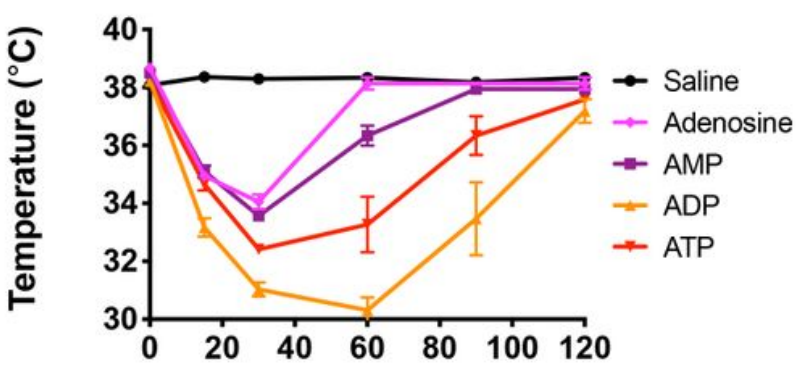

Minutes post injection

\section{Figure 4}

Body Temperature, Bioenergetic, and Behavioral Responses to Acute Hyperpurinergia. A. Male C57BL/6J mice (nucleotide dose $=0.5 \mu \mathrm{mol} / \mathrm{g}$ body weight, $\mathrm{n}=6$ per group, 5-6 months old), B. Female C57BL/6J mice $(\mathrm{n}=6$ per group, 5-6 months old). Intravenous (IV) vs intraperitoneal (IP) dosing (C and D, ATP dose $=0.5 \mu \mathrm{mol} / \mathrm{g}, \mathrm{n}$ $=6$ females per group, 5 months old), C. Body temperature response, D. Behavioral response. Gender-specific differences $(\mathrm{E}-\mathrm{H}$, temperatures measured at 15 minutes post-injection with $0-0.2 \mu \mathrm{mol} / \mathrm{g}$ ATP, $\mathrm{n}=6-8$ mice/group) E. Females were more sensitive to the hypothermic effects of ATP, F. Males were more sensitive to the hypothermic effects of ADP, G. Males and females were equally sensitive to the hypothermic effects of AMP, H. Males and females were equally sensitive to the hypothermic effects of adenosine. Behavioral responses $(\mathrm{I}$ and $\mathrm{J})$, I. The behavioral response to high-dose ATP was the same in males and females (dose = $0.5 \mu \mathrm{mol} / \mathrm{g}, \mathrm{n}=10 \mathrm{per}$ group), J. Dose-response curves at non-saturating ATP doses revealed that males were more sensitive to the behavioral effects of hyperpurinergia (PBRS scores measured at 15 minutes post-ATP, $n$ $=6$ per group, 5- 6 months old). CLAMS cage analysis of bioenergetics (K-N, ATP dose $=0.5 \mu \mathrm{mol} / \mathrm{g}, \mathrm{n}=6$ per group, 28-week old C57BL/6J females), $\mathrm{K}$. The basal metabolic rate measured as the rate of oxygen utilization (VO2) was decreased by $74 \%$ after ATP injection, L. The rate of $\mathrm{CO} 2$ production was decreased by $76 \%$ after ATP injection, $M$. The respiratory exchange ratio (RER) dropped from 0.84 to 0.70 after ATP injection compared to saline, N. ATP injection decreased exploratory activity as measured by light beam breaks compared to saline. Abbreviations: PBRS-purinergic behavioral response scale, SAL-saline, CLAMScomprehensive laboratory animal monitoring system. RER-respiratory exchange ratio = VCO2/VO2 


\section{Figure 5A-D.}
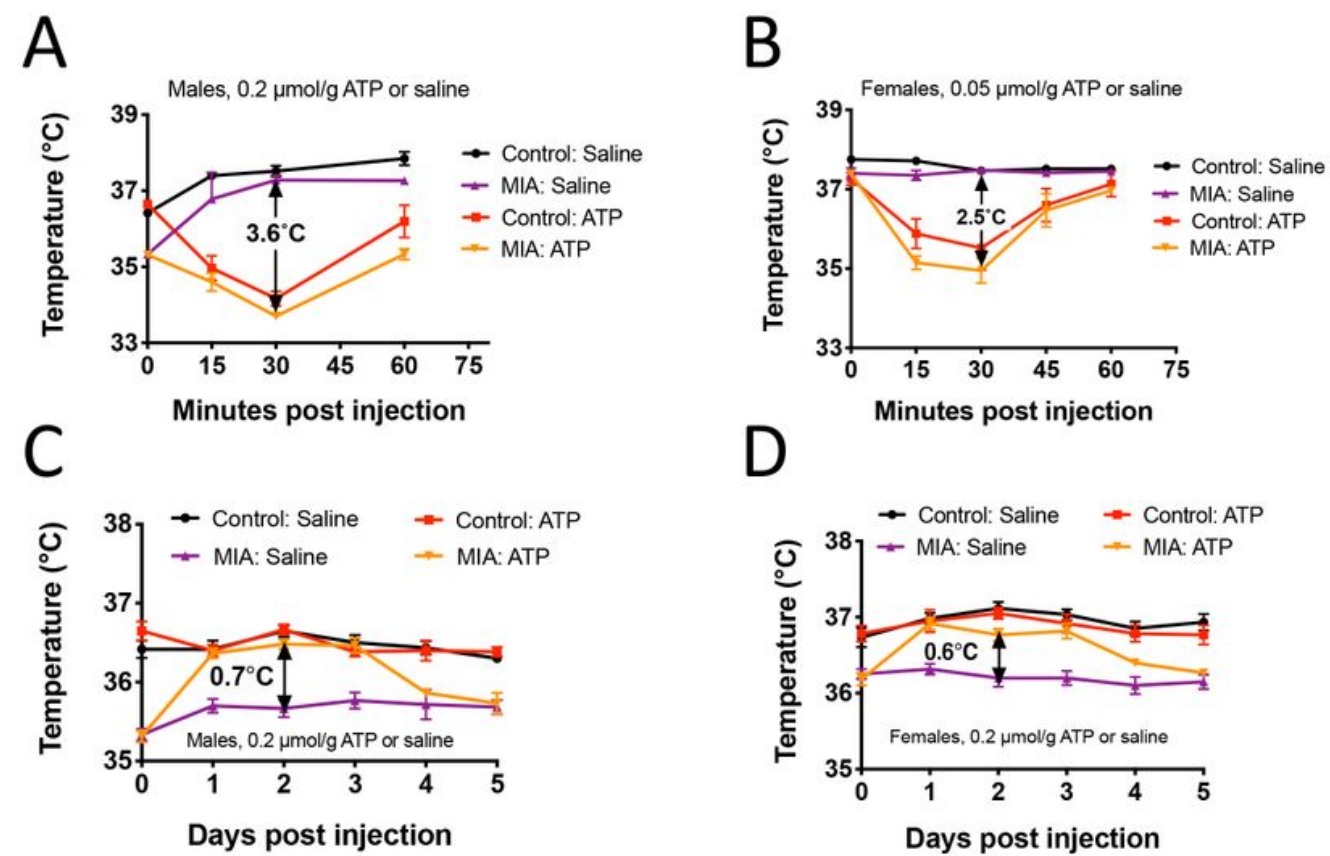

\section{Figure 5}

Latent Memory Response to ATP and Poly(IC) in the MIA Mouse Model of ASD. The acute 1-hour response to postnatal challenge with ATP ( $A$ and $B, n=6$ per group) A. Acute response in males, $B$. Acute response in females. The subacute 5-day response to postnatal challenge with ATP ( $C$ and $D, n=6$ per group, 8-9 months old) C. Five-day response to ATP in males, D. Five-day response to ATP in females, E. The triphasic 1-month response to postnatal challenge with poly(IC) (dose $=2 \mathrm{mg} / \mathrm{kg}, \mathrm{n}=6$ males per group, 8-9 months old). Abbreviations: MIA-maternal immune activation mouse model with ASD-like behaviors, Poly(IC)-poly inosinic:cytosinic acid double strand RNA.

\section{Supplementary Files}

This is a list of supplementary files associated with this preprint. Click to download.

- SupplementaryInformation.docx

- MolAutCoverLetter82120.pdf

- SupplementaryInformationMolAut82120.pdf

- SupplementalTablesS1S12.xlsx 